\title{
Identification of Rate, Extent, and Mechanisms of Hot Metal Resulfurization with $\mathrm{CaO}-\mathrm{SiO}_{2}-\mathrm{Na}_{2} \mathrm{O}$ Slag Systems
}

\author{
TERO VUOLIO, VILLE-VALTTERI VISURI, TIMO PAANANEN, \\ and TIMO FABRITIUS
}

\begin{abstract}
The resulfurization of hot metal has not been comprehensively studied in literature. This study presents an experimental and mathematical modeling study of resulfurization in thermodynamic and kinetic point of view. The rate, extent, and mechanisms of resulfurization were evaluated by analyzing concurrently the physical properties and sulfur-extracting ability of the slag. Experiments were conducted in a chamber furnace in an argon atmosphere, and the hot metal was sampled with pre-defined basis. The experiments were continued until the metal-slag system reached an apparent thermodynamic equilibrium. To obtain a quantitative measure on the effect of system properties on the rate and extent of resulfurization, the results of this study were combined with previous studies handling the sulfide capacities of $\mathrm{Na}_{2} \mathrm{O}-\mathrm{SiO}_{2}$ and $\mathrm{CaO}-\mathrm{SiO}_{2}-\mathrm{Na}_{2} \mathrm{O}$ slag systems. The sulfide capacities of the slag and corresponding metal-slag sulfur partition ratios were mathematically modeled with data-driven techniques such as multiple linear and non-linear regression and artificial neural networks. Finally, with the help of these, to study the kinetics of resulfurization, a simple mechanistic reaction model was derived. The results suggest that resulfurization of hot metal follows 1st-order kinetics and that the rate and extent can be regulated through the control of the associated thermodynamic driving force and by modifying the physical properties of the slag. The rate-limiting factor was found to be determined by the morphology of the slag phase.
\end{abstract}

https://doi.org/10.1007/s11663-019-01600-5

(C) The Author(s) 2019

\section{INTRODUCTION}

IN blast furnace-based steelmaking, sulfur is considered as one of the main impurities in hot metal. The removal of sulfur is commonly conducted with powder injection. In powder injection, a desulfurization reagent is injected into hot metal with the help of a carrier gas through an immersed lance. Suitable desulfurization reagents include lime, calcium carbide, magnesium, soda ash, limestone, and zinc oxide. Hot metal desulfurization with powder injection consists of two main reactions ${ }^{[1]}$ :

(i) Transitory contact reaction (reagent-metal)

(ii) Permanent contact reaction (metal-slag)

TERO VUOLIO, VILLE-VALTTERI VISURI, and TIMO FABRITIUS are with the Process Metallurgy Research Unit, University of Oulu, P.O. Box 4300, FI-90014, Finland. Contact email: tero.vuolio@oulu.fi TIMO PAANANEN is with the SSAB Europe Oy, Rautaruukintie 155, P.O. Box 93, FI-92101, Raahe, Finland.

Manuscript submitted February 13, 2019.

Article published online May 8, 2019.
In the thermodynamic calculations conducted by Pal and Patil ${ }^{[1]}$ it was suggested that the majority of sulfur is extracted via the transitory contact reaction, but the equilibrium sulfur content is often higher for the permanent contact reaction. ${ }^{[1]}$ This implies the existence of a thermodynamic driving force for the inverse reaction that is referred to as resulfurization. The kinetics of the desulfurization of hot metal via a permanent phase contact has been studied intensively for $\mathrm{Na}_{2} \mathrm{O}$-containing slag systems in References 2 through 4. However, the resulfurization of hot metal has drawn less attention.

Early observations on the resulfurization of hot metal in the case of the $\mathrm{CaO}-\mathrm{SiO}_{2}-\mathrm{Na}_{2} \mathrm{O}$ system were made in the study of Schenck et al. ${ }^{[2]}$ The authors conducted experiments on desulfurization in the Fe-C-S system and identified that the changes in the sulfur and iron oxide contents of the slag followed were found to be associated with each other, but the authors did not present the mechanisms behind the resulfurization reaction. ${ }^{[2]} \mathrm{Liu}$ et al. ${ }^{[5]}$ studied the kinetics of resulfurization of steel in the $\mathrm{CaO}-\mathrm{FeO}-\mathrm{SiO}_{2}-\mathrm{CaS}$ slag system. In their study, it was established that resulfurization of steel follows 1st-order reaction kinetics, and is controlled by mass 
transfer in the slag phase. The authors also suggest that the increased liquid phase fraction in the slag phase could increase the rate of resulfurization due to the increased rate of mass transfer at the interface. ${ }^{[5]}$ However, the authors did not consider the fact that the studied fluxes $\left(\mathrm{FeO}\right.$ and $\left.\mathrm{CaF}_{2}\right)$ both decrease the sulfide capacity according to van Niekerk and Dippenaar $^{[6]}$ and Schenck et al. ${ }^{[2]}$ This being so, the rate of resulfurization increases due to the increase in the thermodynamic driving force, which assumedly has a greater effect on the molar flux of sulfur through the metal-slag interface than the increased rate of mass transfer associated to the liquid phase portion. Also in their study, the sulfur content of the slag phase was only 0.12 wt pet, ${ }^{[5]}$ which would imply a low thermodynamic driving force in the case of high carbon and silicon contents in the metal phase.

Because of the tighter quality specifications of hot metal and steel, there is a need for the detailed characterization of sulfur balance at every stage of the production chain. For these reasons, the rate and extent of resulfurization after hot metal desulfurization needs to be studied further. The aim of this work was to study resulfurization using laboratory-scale equipment to assess rate-controlling factors and means to affect the phenomenon. To this aim, a mathematical description of accounting the main mechanisms of resulfurization was formulated. A comprehensive evaluation of the sulfide capacity of the slag phase was made with data-driven techniques to evaluate the significance of the slag composition and thus the sulfide capacity on the rate of reaction.

\section{MATHEMATICAL MODEL FOR HOT METAL RESULFURIZATION}

\section{A. Kinetic Basis of Resulfurization via Permanent Phase Contact}

As the rate of resulfurization is controlled by mass transfer in the slag phase, the sulfide capacity of the slag phase controls the rate of resulfurization through the thermodynamic driving force. In order for an inverse desulfurization reaction to occur, the following inequality would have to be true:

$$
L_{\mathrm{S}, t} \gg L_{\mathrm{S}, \text { eq }},
$$

where $L_{\mathrm{S}, t}$ is the sulfur partition ratio between the slag and the metal phase at time instant $t$ and $L_{\mathrm{S} \text {,eq }}$ is the sulfur partition ratio in case of the metal-slag equilibrium state. To clarify, the sulfur partition ratio is determined as

$$
L_{\mathrm{S}}=\frac{(\text { pet } \mathrm{S})}{[\operatorname{pct} \mathrm{S}]} \text {. }
$$

If the sulfur concentration of the top slag is significantly larger than the equilibrium sulfur concentration in the top slag, there is a thermodynamic potential for resulfurization and the transfer rate is controlled by mass transfer of sulfur in the slag phase. The concentration of sulfur in the slag phase can be written assuming a 1st-order rate of reaction:

$$
\frac{\mathrm{d}(\mathrm{S})}{\mathrm{d} t}=-k_{\mathrm{tot}}\left((\operatorname{pct} \mathrm{S})-(\operatorname{pct} \mathrm{S})_{\mathrm{eq}}\right)
$$

where $k_{\text {tot }}$ is the rate constant for the resulfurization reaction via a permanent phase contact; (pct $\mathrm{S}$ ) is the sulfur content in the slag phase; and (pct $\mathrm{S})_{\text {eq }}$ is the equilibrium sulfur content in the slag phase. In a steady flow field, the value of $k_{\text {tot }}$ can be approximated with

$$
k_{\mathrm{tot}}=\frac{D_{(\mathrm{S})}}{\delta_{\mathrm{S}}} \frac{A_{\mathrm{S}-\mathrm{M}}}{V_{\mathrm{S}}},
$$

where $A_{\mathrm{S}-\mathrm{M}}$ is the interfacial area between the slag and the metal phases; $V_{\mathrm{S}}$ is the volume of the slag phase; $\delta_{\mathrm{S}}$ is the thickness of the diffusion boundary layer; and $D_{(\mathrm{S})}$ is the diffusion coefficient of sulfur in the slag phase. The temperature dependency of diffusion in the slag phase was assumed to follow Arrhenius' type of equation. Integrating Eq. [3] with respect to time and rearranging yields the following expression for the time constant of the resulfurization reaction:

$$
k_{\mathrm{tot}}=-\frac{1}{t} \ln \left(\frac{(\operatorname{pct} \mathrm{S})_{t .}-(\operatorname{pctS})_{\mathrm{eq}}}{(\operatorname{pctS})_{0}-(\operatorname{pctS})_{\mathrm{eq}}}\right) \text {. }
$$

The value of the rate constant of desulfurization has been proposed to correlate with the sulfide capacity of the slag. Choi et al. ${ }^{[3]}$ and later on Tong et al. ${ }^{[4]}$ proposed the following experimental expression for the interaction of rate constant of desulfurization in $\mathrm{CaO}-\mathrm{SiO}_{2}-\mathrm{Al}_{2} \mathrm{O}_{3}-\mathrm{Na}_{2} \mathrm{O}$-system and sulfide capacity

$$
k_{\mathrm{tot}}^{\prime}=b_{i} C_{\mathrm{S}}+b_{0},
$$

where $C_{\mathrm{S}}$ is the sulfide capacity; $b_{i}$ is the regression coefficient for variable $i ; b_{0}$ is the bias term; and $k_{\text {tot }}^{\prime}$ is the apparent rate constant for the desulfurization reaction. The proposed approach is problematic for several reasons. Firstly, the sulfide capacity is related non-linearly with the physical properties of the slag phase, for example, with the liquid phase fraction, and secondly the approach concerns the mass transfer coefficients, activities of the species, and dimensions of the system as constants, which can be seen from the definition of the total mass transfer resistances for the permanent contact reaction

$$
k_{\mathrm{tot}}^{\prime}=\frac{A}{V}\left(\frac{1}{\frac{1}{\beta_{[\mathrm{S}]}}}+\frac{1}{\frac{\rho^{*}}{\frac{K_{1} C_{\mathrm{S}} a_{[\mathrm{O}]}^{\mathrm{H}}}{f_{[\mathrm{S}}^{\mathrm{H}}} \beta_{(\mathrm{S})}}}\right),
$$

where $\beta_{[\mathrm{S}]}$ is the mass transfer coefficient for sulfur in the metal phase; $\rho^{*}$ is the density ratio between slag and metal; $\beta_{(\mathrm{S})}$ is the mass transfer coefficient of sulfur in the slag phase; $a_{[\mathrm{O}]}^{\mathrm{H}}$ is the Henrian activity of oxygen in the metal phase; $A$ is the interfacial area for mass transfer; and $V$ is the volume of the slag phase. 


\section{B. Thermodynamic Properties}

A major problem in the prediction of sulfide capacity of the slag phase is the methodology for determining the activity of oxygen at the metal-slag interface. Typically, this problem is solved by assuming that the activity of oxygen at the interface corresponds to the activity of oxygen at equilibrium. Thus, the activity calculations can be carried out by assuming a reversible oxidation reaction to occur at the interface. In the case of a hot metal with high $\mathrm{C}$ and $\mathrm{Si}$ contents, the equilibrium expression for the equilibrium activity of oxygen can be derived based on the equilibrium constants of either C-CO or $\mathrm{Si}_{-} \mathrm{SiO}_{2}$ as follows ${ }^{[45]}$ :

$$
\begin{aligned}
\log _{10} \mathrm{a}_{[\mathrm{O}]}^{\mathrm{H}}= & -\frac{1}{2} \log _{10} K_{\left(\mathrm{SiO}_{2}\right)}-\frac{1}{2} \log _{10}\left(f_{[\mathrm{Si}]}^{\mathrm{H}}[\mathrm{pct} \mathrm{Si}]\right) \\
& +\frac{1}{2} \log _{10} a_{\left(\mathrm{SiO}_{2}\right)}^{\mathrm{R}}, \\
\log _{10} \mathrm{a}_{[\mathrm{O}]}^{\mathrm{H}}=- & \log _{10} K_{\{\mathrm{CO}\}}+\log _{10} p_{\mathrm{CO}}-\log _{10}\left(f_{[\mathrm{C}]}^{\mathrm{H}}[\mathrm{pct} \mathrm{C}]\right) .
\end{aligned}
$$

The activities of metal and slag species are defined with Henrian and Raoult's law, respectively. The definitions of the Raoultian and Henrian activities for a compound $i$ are given as follows ${ }^{[46,47]}$ :

$$
\begin{gathered}
a_{(i)}^{\mathrm{R}}=\gamma_{i}\left(x_{i}\right), \\
a_{[i]}^{\mathrm{H}}=f_{i}[\operatorname{pct} i],
\end{gathered}
$$

where $\gamma_{i}$ is the Raoultian activity coefficient for component $i ; x_{i}$ is the molar fraction of component $i$ in the slag phase; and $f_{i}$ is the Henrian activity coefficient. The activity coefficient of a component $i$ in a regular solution can be calculated by applying a model proposed by Ban- $\mathrm{Ya}^{[48]}$.

$$
R T \ln \gamma_{i}=\sum_{j} \alpha_{i j} \hat{X}_{j}^{2}+\sum_{j} \sum_{k}\left(\alpha_{i j}+\alpha_{i k}-\alpha_{j k}\right) \hat{X}_{j} \hat{X}_{k}+\Delta G_{\mathrm{C}}^{\circ},
$$

where $\alpha_{i j}$ is the interaction energy between two corresponding cations $(i$ and $j) ; \hat{X}_{i}$ is the cation fraction of $i$; and $\Delta G_{\mathrm{C}}^{\circ}$ is the conversion factor of the activity coefficient between a hypothetical regular solution and a real solution $(\mathrm{J} / \mathrm{mol})$. The interaction energies for the slag components were extracted from Reference 48 . The activity coefficient based on the Henrian standard state is calculated with WLE formalism. The interaction coefficients for Eqs. [32] and [33] are extracted from Reference 47.

$$
\log _{10} f_{i}^{\mathrm{H}}=\sum_{j=1}^{n_{j}} e_{i}^{j}[\mathrm{pct} j] .
$$

\section{Sulfide Capacity of the Slag Phase}

The sulfide capacity is a measure for the sulfur-extracting capacity of the slag phase in a situation where the slag and the metal or slag and gas phase are in thermodynamic equilibrium. The sulfide capacity of the slag phase can be defined based on either one of the following reactions ${ }^{[7]}$ :

$$
\begin{gathered}
\frac{1}{2}\left\{\mathrm{~S}_{2}\right\}+\left(\mathrm{O}^{2-}\right)=\left(\mathrm{S}^{2-}\right)+\frac{1}{2}\left\{\mathrm{O}_{2}\right\}, \\
{[\mathrm{S}]+\left(\mathrm{O}^{2-}\right)=\left(\mathrm{S}^{2-}\right)+[\mathrm{O}] .}
\end{gathered}
$$

The expression for the sulfide capacity of the slag phase can be derived based on the equilibrium constants aforementioned:

$$
\begin{gathered}
C_{\mathrm{S}}=(\operatorname{pctS}) \sqrt{\frac{p_{\left\{\mathrm{O}_{2}\right\}}}{p_{\left\{\mathrm{S}_{2}\right\}}}}, \\
C_{\mathrm{S}}^{\prime}=(\operatorname{pctS}) \frac{a_{[\mathrm{O}]}^{\mathrm{H}}}{a_{[\mathrm{S}]}^{\mathrm{H}}},
\end{gathered}
$$

where $C_{\mathrm{S}}^{\prime}$ is the sulfide capacity of the slag phase defined based on the metal-slag equilibrium and $a_{[\mathrm{S}]}^{\mathrm{H}}$ is the activity of sulfur in the metal phase and $p_{i}$ is the partial pressure of a compound $i$. The relation can be simplified further to Reference 7 :

$$
\log _{10} C_{\mathrm{S}}^{\prime}=\log _{10} C_{\mathrm{S}}-\frac{935}{T}+1.375 .
$$

In reference to the expression of equilibrium distribution of sulfur with respect to slag and metal phases, the formulation for the sulfide capacity of the slag phase with respect to sulfur partition ratio can be given as follows:

$$
\begin{aligned}
\log _{10} C_{\mathrm{S}}= & \log _{10} L_{\mathrm{S}}+\log _{10} a_{[\mathrm{O}]}^{\mathrm{H}}+\frac{935}{T}-1.375 \\
& -\log _{10} f_{[\mathrm{S}]}^{\mathrm{H}},
\end{aligned}
$$

where $f_{[\mathbf{S}]}^{\mathrm{H}}$ is the activity coefficient of sulfur in the metal phase.

A vast amount of semi-empirical or theoretical models have been developed for predicting the sulfide capacity of the slag phase. ${ }^{[6-30]}$ The theoretical models intend to describe the effect of chemical interactions between the slag ions and molecules, ${ }^{[9,12,20,21]}$ whereas semi-empirical correlations use data-driven fitting techniques, namely, the multiple linear regression or artificial neural networks, to identify the effect of slag composition and system properties on the sulfide capacity. ${ }^{[6-8,10,11,13-20,23-30]}$ The advantage of semi-empirical models compared to theoretical ones is a lower computational complexity and usually a more sensible model formulation, thus making them more applicable as a part of dynamic process models. In the case of semi-empirical models, probably the most common variable that is used for capturing the interactions between the slag composition, system properties, and sulfide capacity is the optical basicity of the slag. ${ }^{[7,8,10,11,13]}$ The optical basicity of the slag can be expressed in such a way that each of the cation fractions is weighted by the corresponding optical basicity of the compound ${ }^{[8]}$. 


$$
\Lambda=\sum_{i=1}^{k} \Lambda_{i} \hat{X}_{i}
$$

where $\hat{X}_{i}$ is the cation fraction of the component $i$ in the slag phase and $\Lambda$ is the optical basicity of the slag phase. The cation fraction of a slag component $i$ is given as ${ }^{[8]}$ :

$$
\hat{X}_{i}=\frac{n X_{i}}{\sum_{i=1}^{k} n X_{i}},
$$

where $n$ is the number of oxygen atoms in the corresponding component and $k$ is the number of components in the slag phase. To identify the cross-interaction of temperature and chemical composition on the sulfide capacity of the slag phase, Sosinsky and Sommerville ${ }^{[8]}$ expanded the concept by combining the data gathered from multiple sources. In their study, the prediction model for sulfide capacity of the slag phase is given as ${ }^{[8]}$

$$
\log _{10} C_{\mathrm{S}}=\left(\frac{22690-54640 \Lambda}{T}\right)+43.6 \Lambda-25.2,
$$

where $C_{\mathrm{S}}$ is the sulfide capacity of the slag phase; $\Lambda$ is the optical basicity of the slag phase; and $T$ is temperature of the slag. Despite applicability for wide range of different slag compositions and temperatures, the Sosinsky and Sommerville model has often been found to be ill-suited for predicting the sulfide capacities of $\mathrm{Na}_{2} \mathrm{O}$ $\mathrm{SiO}_{2}{ }^{[10,11,13]}$ and $\mathrm{CaO}-\mathrm{SiO}_{2}-\mathrm{Na}_{2} \mathrm{O}$ systems ${ }^{[6]}$ as well as the sulfide capacity in particular of slag systems in which $\mathrm{CaO}$ content is well above the saturation limit. ${ }^{[8]}$ Later on, Young et al. ${ }^{[7]}$ introduced a piecewise-defined quadratic formulation of sulfide capacity with respect to optical basicity, which is given as ${ }^{[7]}$ oxygen content and the activity coefficient of the dissolved sulfides in the slag is given in the model with a following relation ${ }^{[17]}$ :

$$
\frac{a_{\mathrm{O}^{2-}}}{f_{\mathrm{S}^{2-}}}=\exp \left(-\frac{\varepsilon}{R T}\right),
$$

where $\varepsilon$ is a model parameter that is linearly dependent on the molar fractions of the slag compounds as well as on the interactions of cation fractions of slag compounds and temperature of the slag. Thus, the expression for the parameter can be written as ${ }^{[14]}$

$$
\varepsilon=\sum X_{i} \varepsilon_{i}+\varepsilon_{\text {mix }}
$$

By assuming that the $\mathrm{Ca}^{2+}$ content has a quadratic interaction with the sulfide capacity, the parameterized expression for the $\varepsilon$ in the case of system under study would be

$$
\begin{aligned}
\varepsilon= & X_{\mathrm{CaO}^{\varepsilon}} \mathrm{Ca}^{2+}+X_{\mathrm{Na}_{2} \mathrm{O} \varepsilon_{\mathrm{Na}^{+}}+X_{\mathrm{SiO}_{2}} \varepsilon_{\mathrm{Si}^{4+}}} \\
& +y^{\mathrm{Ca}^{2+}} y^{\mathrm{Na}^{+}}\left(b_{0}+b_{1} T\right)+y^{\mathrm{Ca}^{2+}} y^{\mathrm{Si}^{4+}}\left(b_{2}+b_{3} T\right) \\
& +y^{\mathrm{Na}^{+}} y^{\mathrm{Si}^{4+}}\left(b_{4}+b_{5} T\right) \\
& +y^{\mathrm{Ca}^{2+}} y^{\mathrm{Si}^{4+}} y^{\mathrm{Na}^{+}}\left(b_{6}+b_{7} T+b_{8} y^{\mathrm{Ca}^{2+}}\right) .
\end{aligned}
$$

The advantage of the approach is that it describes all the possible cation interactions for the slag compounds and has been proven fairly accurate. ${ }^{[14-17]}$ However, the previous studies do not address the $\mathrm{CaO}-\mathrm{SiO}_{2}-\mathrm{Na}_{2} \mathrm{O}$ system, and therefore some of the parameters have not been previously identified. For this reason, the performance of the model is evaluated by making use of the parameters given in literature $\mathrm{e}^{[14-17]}$ as well as with the parameters that are identified based on the sulfide

$$
\log _{10} C_{\mathrm{S}}=\left\{\begin{array}{cc}
-23.82 \Lambda^{2}+42.84 \Lambda-\frac{11710}{T}-0.02 \cdot\left(\mathrm{SiO}_{2}\right)-0.02\left(\mathrm{Al}_{2} \mathrm{O}_{3}\right)-13.913, & \Lambda<0.8 \\
0.72 \Lambda^{2}+0.48 \Lambda-\frac{(1697-2587 \Lambda)}{T}+0.02 \cdot\left(\mathrm{SiO}_{2}\right)-0.0005\left(\mathrm{Al}_{2} \mathrm{O}_{3}\right)-0.63, & \Lambda \geq 0.8
\end{array}\right.
$$

Despite simplifications in the model formulation, the model given in Young et al. ${ }^{[7]}$ performs reasonably well in validation with an external data set. A common problem of the model formulations is that models employing the concept of optical basicity do not extrapolate well to slag systems outside the studied composition range. In fact, there are numerous slag compositions that have nearly equal optical basicities, but are known to have unequal sulfide capacities; for instance, there is a large difference in the sulfide capacities of $\mathrm{CaO}-\mathrm{SiO}_{2}$ and $\mathrm{Na}_{2} \mathrm{O}-\mathrm{SiO}_{2}$ systems that cannot be explained by differences in optical basicity. ${ }^{[6]}$ To address this shortcoming, a thermostatistical model, often referred as the KTH model has been proposed for a thoroughly molten slag. The model is based on the assumption that the sulfide capacity of the slag is defined by equilibrium expression for the pure liquid $\mathrm{FeO}$ and with the experimental parameter $\varepsilon$ that is dependent on the composition and temperature of the slag. ${ }^{[14-17]}$ The ratio of the free capacity measurements for $\mathrm{Na}_{2} \mathrm{O}-\mathrm{SiO}_{2}$ and $\mathrm{CaO}-\mathrm{SiO}_{2}-$ $\mathrm{Na}_{2} \mathrm{O}$ slag systems. The data for the identification are extracted and combined from References 6, 10, 11, and 31.

The effect of sodium oxide $\left(\mathrm{Na}_{2} \mathrm{O}\right)$ on the rate of desulfurization via transitory and permanent phase contact and on the sulfide capacity of the slag has been reported in several studies. ${ }^{[2-5,10,11,13,30,31]}$ It has been concluded that the sulfide capacities of $\mathrm{Na}_{2} \mathrm{O} / \mathrm{SiO}_{2}-$ based slags are higher than those of $\mathrm{CaO} / \mathrm{SiO}_{2}$-based slags ${ }^{[3,5-7]}$ and the rate of desulfurization increases with the increase of the $\mathrm{Na}_{2} \mathrm{O}$ content in the slag. ${ }^{[2,3]}$ The activity of $\mathrm{CaO}$ has been found to be increased with the activity of $\mathrm{Na}_{2} \mathrm{O}$ in the slag phase, ${ }^{[30,32]}$ which can be associated to increased dissolved fraction of $\mathrm{CaO}$. As regards the sulfide capacity of $\mathrm{Na}_{2} \mathrm{O}-\mathrm{SiO}_{2}$ and $\mathrm{CaO}-\mathrm{SiO}_{2}-\mathrm{Na}_{2} \mathrm{O}$-systems, several authors suggest that the $\mathrm{Na}_{2} \mathrm{O} / \mathrm{SiO}_{2}$ ratio is the strongest predictor variable. ${ }^{[6,13]}$ In the studies of Chan and Fruehan ${ }^{[10,11]}$ and 
Kunisada and Iwai, ${ }^{[13]}$ it was observed that the sulfide capacity of a binary $\mathrm{Na}_{2} \mathrm{O}-\mathrm{SiO}_{2}$ slag system in different temperatures can be expressed with the following correlations:

$$
\begin{aligned}
\log _{10} C_{\mathrm{S}} & =b_{1} \Lambda+b_{0} \\
& = \begin{cases}11.66 \Lambda-11.86^{[10]} & T=1423.15 \mathrm{~K} \\
11.86 \Lambda-11.33^{[11]} & T=1673.15 \mathrm{~K}, \quad[27] \\
27.00 \Lambda-21.20^{[13]} & T=1773.15 \mathrm{~K}\end{cases}
\end{aligned}
$$

where $b_{1}$ and $b_{0}$ are experimentally determined regression coefficients fitted as a function of system temperature. However, as the experimental results are fitted for the binary $\mathrm{Na}_{2} \mathrm{O}-\mathrm{SiO}_{2}$-system, the coefficient related to the interaction of optical basicity and sulfide capacity does not include the effect of various basic compounds, e.g., $\mathrm{CaO}$, on sulfide capacity. To include the effect of $\mathrm{CaO}$ on the sulfur partition ratio for the $\mathrm{CaO}-\mathrm{SiO}_{2}-\mathrm{Na}_{2} \mathrm{O}$ system, van Niekerk and Dippenaar ${ }^{[6]}$ proposed the following correlation in the $\mathrm{CO}$ atmosphere ${ }^{[6]}$ :

$$
\log _{10} L_{\mathrm{S}}=1.01 \frac{\left(\mathrm{Na}_{2} \mathrm{O}\right)}{\left(\mathrm{SiO}_{2}\right)}-0.07 \frac{(\mathrm{CaO})}{\left(\mathrm{Na}_{2} \mathrm{O}\right)}+0.37 .
$$

The problem of the formula of van Niekerk and Dippenaar ${ }^{[6]}$ is that it does not include the effect of activity of oxygen that is well known to explain the changes in the sulfur partition ratio. A more close inspection of the model formulation and their data reveals the existence of a multicollinearity problem in the formulation, as the coefficient of determination between the predictor variables is $R^{2}=0.87 .{ }^{[6]} \mathrm{A}$ summary of the sulfide capacity models with relevant compositions in reference to blast furnace-based steelmaking has been given in Table I.

\section{An Artificial Neural Network-Based Approach for the Prediction of Sulfide Capacity}

Artificial neural networks (ANN), or just neural networks, are a class of computational models that are inspired by the biological neurons that constitute the natural brains. The neural networks are applied for classification, clustering, or regression problems. The advantage of a neural network-based model is that besides the measurement data, it does not necessarily require any external information on the system's dynamics, ${ }^{[33-35]}$ although the selection of proper input variables and the architecture of a network for predicting complex dynamics often requires extensive work. ${ }^{[35]}$

A neural network usually consists of layers of connected neurons that are referred to as input, hidden, and output layers. A single neuron is, depending on the case, either a linear or non-linear computational unit that includes a summation term and an activation function. The number of neurons and connecting weights in a neural network vary within the complexity and nature of the problem. The most suitable architecture for a neural network is thus case dependent. As a rule of thumb, in reference to literature, it is said that a network, which consists of a single hidden layer with a sigmoid-type activation function and a linear output layer, can approximate an arbitrary, but continuous and twice differentiable function with sufficient accuracy. ${ }^{[36,37]}$ The output of a sigmoid-type activation function is given as

$$
a_{i}=\frac{1}{1+e^{-z_{i}}},
$$

where $a_{i}$ is the output of a hidden neuron $i$ and $z_{i}$ is the input of a hidden neuron $i$. In the case of a single hidden layer, the input of a single hidden neuron can be expressed as a weighted sum of the selected input variables:

$$
z_{i}=\sum_{j=1}^{n} w_{j, i} x_{j}+b_{0, i}
$$

where $w_{j, i}$ is the synaptic weight between the input variable $j$ and the hidden neuron $i ; x_{j}$ is an input variable $j$; and $b_{0, i}$ is the bias term of a hidden neuron $i$; and $n$ is the number of input variables. The output of the hidden neuron $z_{i}$ is then passed to the output layer. In the case of a single variable regression problem, the output layer consists of a single output neuron. In this study, the output neuron constitutes of a linear unit. This being so, the output of the neural net is given by

$$
\hat{y}=\sum_{i=1}^{k} w_{i} z_{i}+b_{0, k+1}
$$

where $k$ is the number of hidden neurons and $b_{0, k+1}$ is the bias of the output neuron. The aforementioned formulation can be intuitively interpreted as a two-step regression model, in which the output of the network corresponds to a multivariable linear regression between a non-linear mapping of the input variable and the output variable.

The procedure, in which the synaptic weights connecting the neurons with each other are solved, is referred to as training. ${ }^{[38]}$ When applying a neural network for regression, a more specific term for the procedure would be supervised training. In supervised training, the synaptic weights of the neural network are identified such that the outputs of the network correspond to the training samples, ergo by minimizing the sum of the prediction residuals. A mathematical expression for this is given $a^{[38]}$

$$
\mathrm{SSE}=\min \sum_{i=1}^{n}\left(y_{i}-\hat{y}_{i}\right)^{2},
$$

where $y_{i}$ is a training sample; $\hat{y}_{i}$ is the neural network output; and $n$ is the number of training samples. The minimization of the objective function can be carried out with a suitable optimization algorithm, which can be roughly divided in gradient-based methods, ${ }^{[38]}$ derivative-free methods, ${ }^{[39]}$ and to hybrid approaches. ${ }^{[40]} \mathrm{A}$ well-known problem in the training of a neural network with a gradient-based method is the tendency for the algorithm to get stuck in the local 


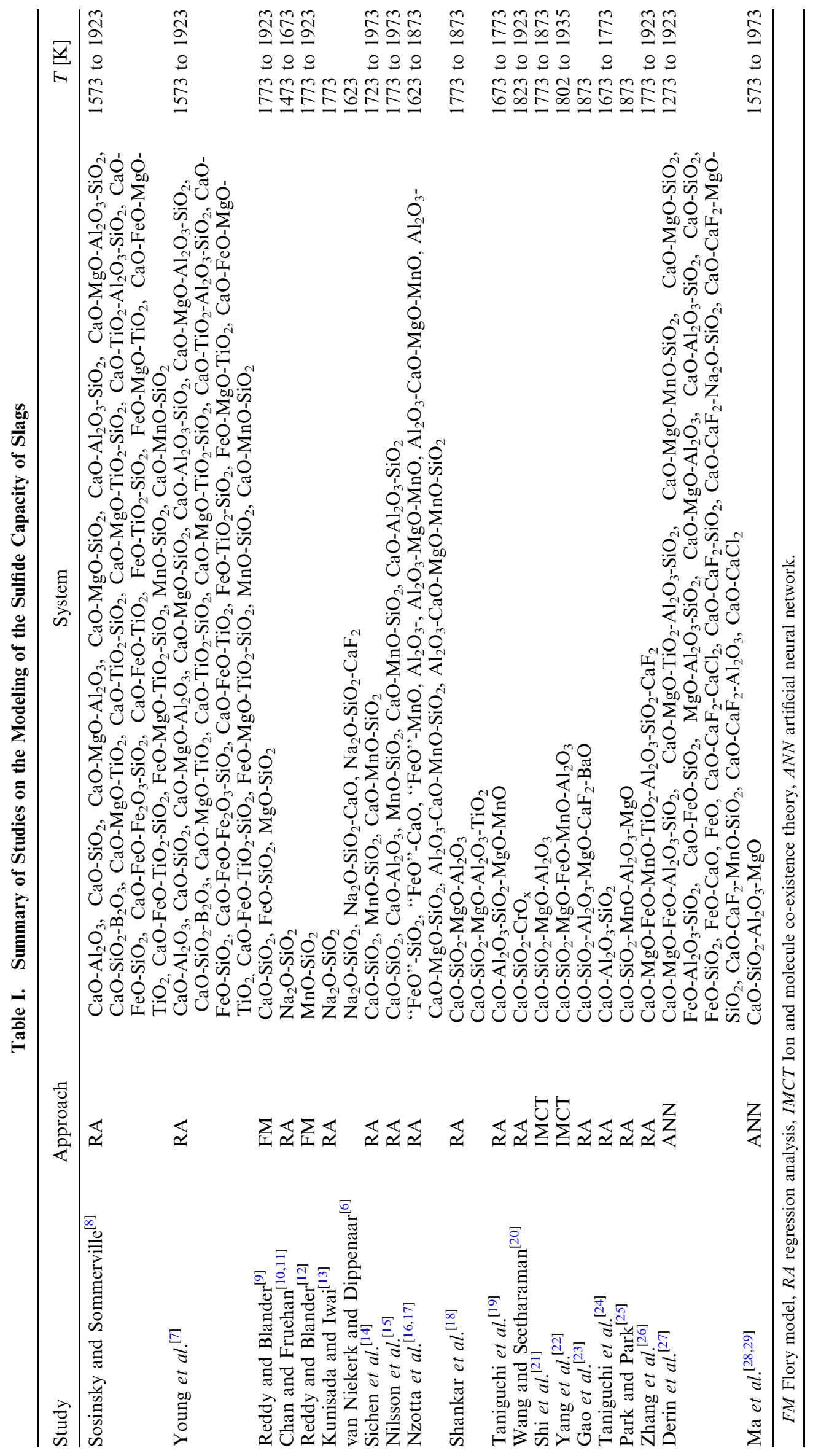




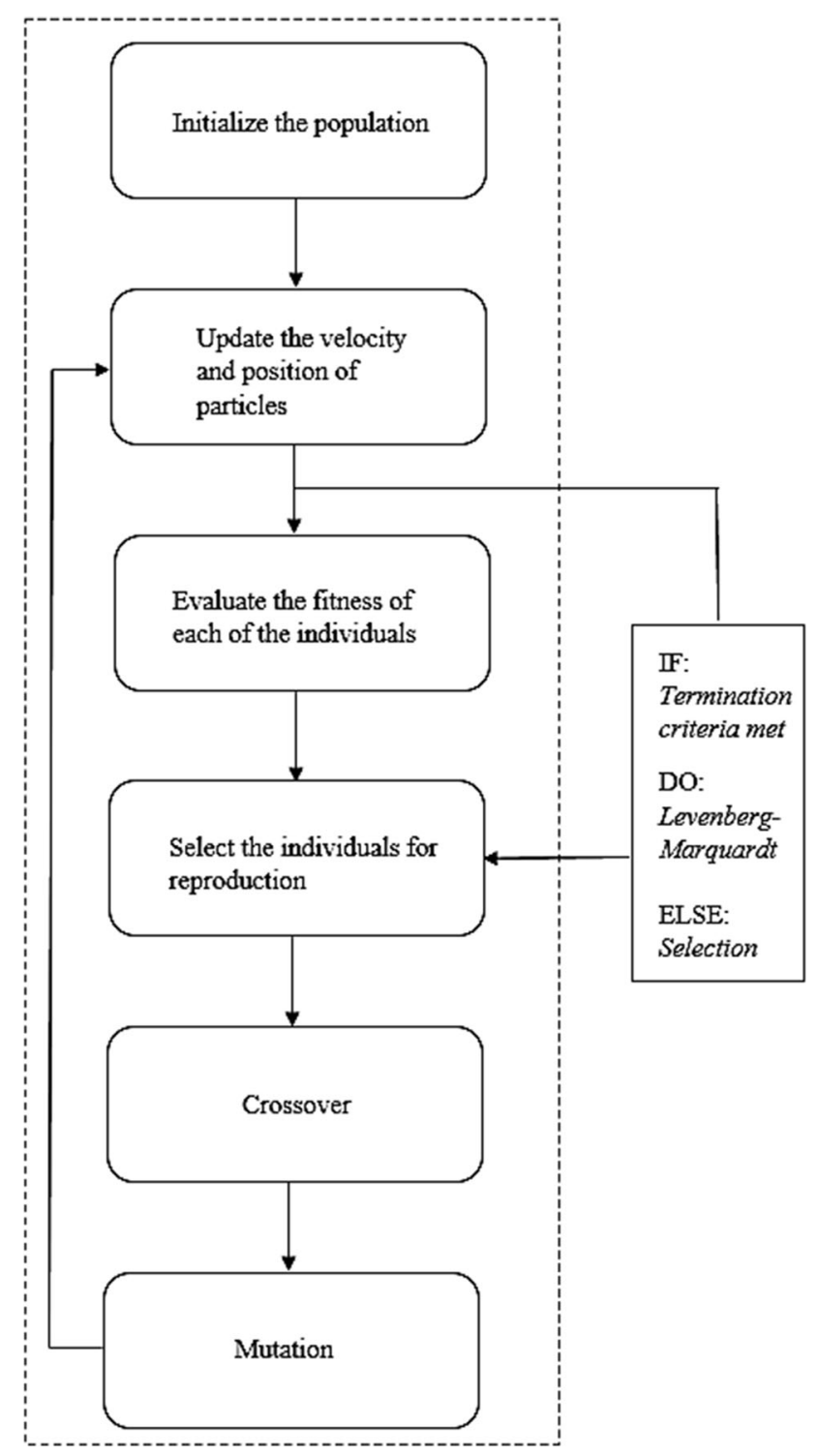

Fig. 1-PSO-GA + LM algorithm.

optima. ${ }^{[38]}$ This is rather usual in the case of real-life data fitting problems, especially when the training data set consists of noise and collinearities, which results in a non-smooth function space and multimodality. To tackle this, a variety of methods have been suggested. An interesting approach is to apply evolutionary search methods in the identification of the neural network synaptic weights. ${ }^{[40]}$ A major advantage of an evolutionary search method compared to gradient-based methods is that the algorithm explores a large search space, while gradient-based methods usually apply a single initial guess in the calculation. However, the evolutionary search methods, such as genetic algorithms tend to converge near the local or global minima, and not to the exact minima. This particular problem could be solved by finishing the optimization with a gradient-based method for which the convergence to the local minima is guaranteed, if the

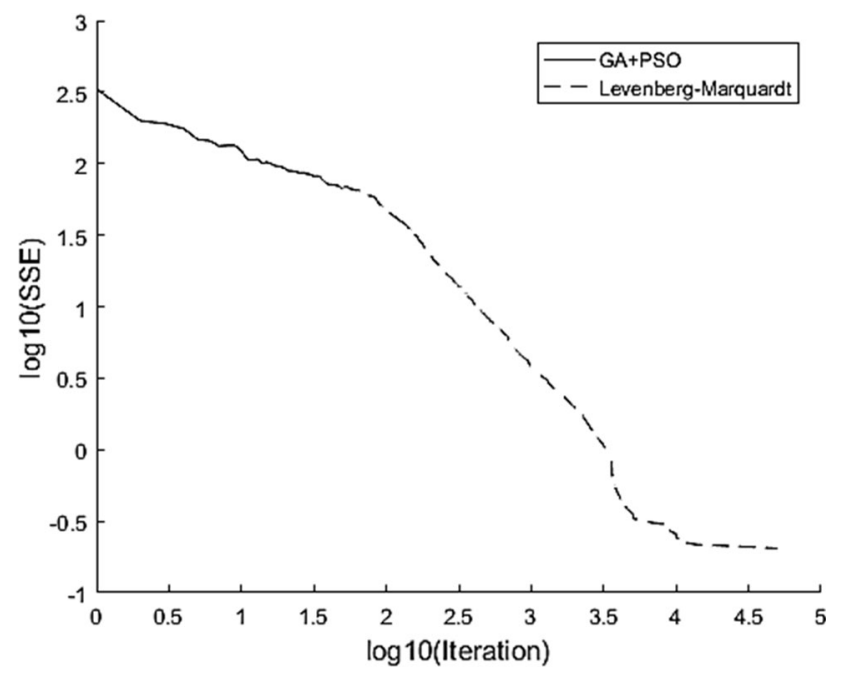

Fig. 2-Convergence of the PSO + GA + LM training algorithm to a minimum of a test function (simplefit.m ${ }^{[44]}$ ).

applied step-size yields a numerically stable convergence. An example of this kind of an approach is applied successfully in a rainfall forecasting by Asadi et al. ${ }^{[40]}$ in which the authors used a real-coded genetic algorithm to generate an initial guess for the steepest descent method. ${ }^{[40]}$ In this work, the concept of the training algorithm is the same, but the initial guess is generated with a combination of a standard particle swarm optimization algorithm ${ }^{[41]}$ and a real-coded genetic algorithm. The proposed algorithm shares some similarities with the algorithms reported, for example, in References 42 and 43.

The advantage of the particle swarm optimization is that the algorithm memorizes the best location in the population, whereas the genetic algorithm is efficient in generating new information in the existing population. ${ }^{[42]}$ The algorithm can provide a desirable initial guess for the gradient-based method. The convergence to a near exact local minimum is ensured by finishing the training with Levenberg-Marquardt algorithm, which is described in more detail in Reference 38. The flowchart of the applied training algorithm is given in Figure 1. The convergence curve presented in Figure 2 is calculated based on the identification of a test function $^{[44]}$ with the neural network that is applied in this study.

A common problem in training a neural network is overfitting. To ensure the good generalizability of a network, the trained network has to be tested on an external data set. Some common situations where a network has a high tendency for overfitting is where there is a sparse distribution of observations or the applied network architecture is far too complicated. A too complicated architecture of a neural network applied to a sparse or simplistic problem is analogous to a simple multivariable linear regression model, in which the number of predictor variables is excessively large, especially when complemented with a small number of observations. 
So far, only a few attempts have been made to predict the sulfide capacity of a multicomponent slag system with a neural network. In the studies of Derin et al. ${ }^{[27]}$ and Ma et al., ${ }^{[28,29]}$ a neural network was applied to predict the sulfide capacity of the slag phase based on the chemical composition, temperature, and partial pressures of oxygen and sulfur in the system. The study of Derin et al. ${ }^{[27]}$ showed that a neural network can be trained using a data set of a multicomponent slag system. Unfortunately, the absence of validation and testing of the model, a disproportionately high coefficient of determination for the training set $\left(R^{2} \approx 1\right)$ and the fact that apparently, the training procedure is repeated for each of the slag systems, and not by combining the data, ${ }^{[27]}$ imply that the model may be subject to overfitting. The studies of $\mathrm{Ma}$ et al. ${ }^{[28,29]}$ tested a high variety of prediction models and conducted a careful cross-validation of the results for each of the network architectures. Despite the merits of the study, the authors applied the sulfur content in the slag phase as well as the partial pressures of the gas phase as the explanatory variables. This obviates the need of a neural network for the prediction of sulfide capacity and the sulfur partition ratio and also could saturate the effect of slag composition on the sulfide capacity. ${ }^{[28,29]}$

In this work, an artificial neural network model (ANN) was constructed as a comparison for the more traditional approaches for the prediction of sulfide capacity. The input variables of the ANN are selected manually with the forward selection procedure by using multivariable linear regression (MLR) as the model basis. In forward selection procedure, the algorithm is initialized with a variable with the highest correlation with the dependent variable. The selection is continued until the prediction and generalization ability of the model does not improve significantly. The model parameters are identified with the Moore-Penrose inversion in the case of MLR models. A least-squares solution for the MLR model parameters is given as ${ }^{[53]}$

$$
\hat{b}=\left(X^{\mathrm{T}} X\right)^{-1} X^{\mathrm{T}} y .
$$

The architecture of the ANN was determined with the cross-validation procedure, in which the network giving the most realistic prediction results based on the training and external validation data sets is selected as the final model. For the validation of the models, the Leave-Multiple-Out-cross-validation was applied. In the validation procedure, the data were split such that 58 pct is used for training and 42 pct for external validation, which excludes the possibility of chance correlation and overfitting, ${ }^{[54]}$ but also assists to evaluate the consistency of the selected, which consequently yields as more stable models. ${ }^{[54,55]}$

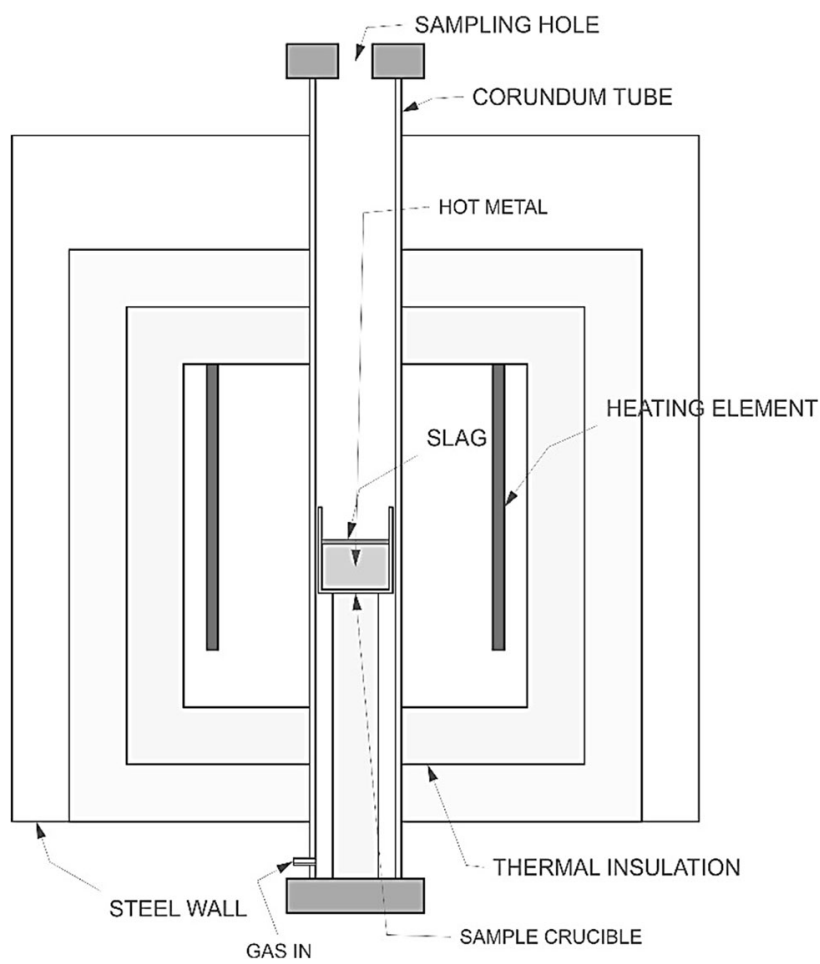

Fig. 3-A schematic illustration of the applied apparatus.

\section{EXPERIMENTAL SET-UP}

To study the resulfurization phenomenon experimentally, high-temperature metal-slag experiments were conducted in a chamber furnace. A description of the experimental apparatus as well as the experimental design is provided below.

\section{A. Apparatus}

A schematic illustration of the experimental apparatus is presented in Figure 3. During the experiments, the temperature of the system was held constant at $1350{ }^{\circ} \mathrm{C}$ $(1623 \mathrm{~K})$. At the beginning of each experiment, the hot metal was heated to a temperature of $\sim 1700{ }^{\circ} \mathrm{C}$ $(1923 \mathrm{~K})$, to ensure the melting of $\mathrm{Fe}$ and thus the dissolution of graphite in the melt. The maximum temperature was held for 2 hours, after which the temperature of the system was decreased to the experimental temperature $1350{ }^{\circ} \mathrm{C}(1623 \mathrm{~K})$. The initial sample of the metal phase was taken at time instant $t=0$ minutes. After taking the initial sample, the slag phase was poured on the hot metal phase through the sampling hole with the help of a quartz tube. The sampling of hot metal was conducted every 5 minutes during the time period of 0 to 20 minutes, and every ten 
Table II. Composition of the Metal Phase in the Experiments

\begin{tabular}{lcccc}
\hline Fe (Wt Pct) & C (Wt Pct) & S (Wt Pct) & Si (Wt Pct) & Mn (Wt Pct) \\
\hline 95.3 & 4.5 & 0.005 & 0.045 & 0.172 \\
\hline
\end{tabular}

Table III. Compositions of the Slag Phase in the Experiments

\begin{tabular}{lcccc}
\hline Slag & $\mathrm{CaO}(\mathrm{Wt}$ Pct) & $\mathrm{Na}_{2} \mathrm{O}(\mathrm{Wt} \mathrm{Pct})$ & $\mathrm{SiO}_{2}(\mathrm{Wt} \mathrm{Pct})$ & $\mathrm{CaS}(\mathrm{Wt} \mathrm{Pct})$ \\
\hline Experiment 1 & 76.2 & 0 & 15.7 & 7.9 \\
Experiment 2 & 73.7 & 3.2 & 15.2 & 7.9 \\
Experiment 3 & 71.2 & 6.3 & 14.7 & 7.9 \\
Experiment 4 & 67.9 & 10.1 & 14.0 & 7.9 \\
\hline
\end{tabular}

Table IV. Dimensional Analysis of the System

\begin{tabular}{|c|c|c|c|}
\hline Dimension & Hot Metal Ladle & Crucible & Ratio \\
\hline Diameter (m) & 2.5 & $4.4 \times 10^{-2}$ & 56.1 \\
\hline Height of the Crucible (m) & 3.6 & $5.5 \times 10^{-2}$ & 64.9 \\
\hline Metal-Slag Interfacial Area $\left(\mathrm{m}^{2}\right)$ & 4.8 & $1.5 \times 10^{-3}$ & 3151.3 \\
\hline Volume $\left(\mathrm{m}^{3}\right)$ & 17.1 & $8.4 \times 10^{-5}$ & $204,547.5$ \\
\hline Weight of the Metal Bath $(\mathrm{kg})$ & 80,000 & 0.45 & $176,902.0$ \\
\hline Density of Hot Metal $\left(\mathrm{kg} / \mathrm{m}^{3}\right)$ & 6900 & 6900 & 1.0 \\
\hline Volume of Hot Metal $\left(\mathrm{m}^{3}\right)$ & 11.6 & $6.6 \times 10^{-5}$ & $176,902.0$ \\
\hline Height of Hot Metal Bath (m) & 2.4 & $4.3 \times 10^{-2}$ & 56.1 \\
\hline Weight of Slag $(\mathrm{kg})$ & 1200 & $6.8 \times 10^{-3}$ & $176,902.0$ \\
\hline Density of Slag $\left(\mathrm{kg} / \mathrm{m}^{3}\right)$ & 3000 & 3000 & 1.0 \\
\hline Volume of Slag $\left(\mathrm{kg} / \mathrm{m}^{3}\right)$ & 0.4 & $2.3 \times 10^{-6}$ & $176,902.0$ \\
\hline Height of Slag $(\mathrm{m})$ & 0.1 & $1.5 \times 10^{-3}$ & 56.1 \\
\hline Area/Volume Ratio $\left(\mathrm{A}_{\mathrm{M}-\mathrm{S}} / \mathrm{V}_{\mathrm{M}}\right)$ & 0.4 & 23.2 & 56.1 \\
\hline
\end{tabular}

minutes during the rest of the experiment, which makes the total duration of the experiment 90 minutes, which according to various authors is held to be a sufficient time to reach the apparent metal-slag equilibrium state. $^{[2-6,10,11]}$

The sulfide capacity for each of the slag phases was determined with the metal-slag equilibrium method. The compounds used in the preparation of the slag phase with corresponding chemical purities were $\mathrm{CaO}$ (99.7 wt pct), $\mathrm{CaS}$ (97 wt pct), $\mathrm{Na}_{2} \mathrm{CO}_{3}$ (99.9 wt pct), and $\mathrm{SiO}_{2}$ (99.7 wt pct). To ensure the dissolution of sulfides in the oxide-melt prior to the tests, the slag phase was pre-treated in a chamber furnace by holding the system at a temperature of $1400{ }^{\circ} \mathrm{C}(1673.15 \mathrm{~K})$ for 2 hours. The rate of change of temperature was $600{ }^{\circ} \mathrm{C} /$ h $(600 \mathrm{~K} / \mathrm{h})$.

\section{B. Experimental Design}

The test series were built by varying the composition of the slag phase. The chemical compositions of the metal and slag phases are presented in Tables II and III. The independent variable in the test series is $\mathrm{Na}_{2} \mathrm{O}$ content of the slag phase, as the other variables $\left(B_{2}\right.$ and CaS content) are held constant. The main dependent variable is the apparent rate constant of the resulfurization reaction $\left(k_{\text {tot }}\right)$ and the sulfur partition ratio $\left(L_{\mathrm{S}}\right)$ at the approximated equilibrium state between the slag and hot metal. The rate constant $\left(k_{\text {tot }}\right)$ for the 1 st-order resulfurization reaction was determined based on the mass balance of sulfur in the slag and metal phases. The mass of sulfur in the slag phase at time instant $t$ can be given implicitly based on the following mass balance:

$$
\begin{aligned}
(\operatorname{pctS})_{t+h, \text { calc. }}= & {\left[(\operatorname{pctS})_{t} m_{0, \text { slag }}-\left([\operatorname{pct~S}]_{t+h}\right.\right.} \\
& \left.\left.-[\operatorname{pct~S}]_{t}\right) m_{\mathrm{Fe}, t}\right] \frac{1}{m_{0, \text { slag }}},
\end{aligned}
$$

where $[\mathrm{S}]_{t+h}$ is the sulfur content in the metal phase at time instant $t+h ;[\mathrm{S}]_{t}$ is the sulfur content in the metal phase at the time instant $t ; m_{0, \text { slag }}$ is the initial mass of the slag phase; $m_{\mathrm{Fe}, t}$ is the mass of the hot metal at time instant $t$; and $h$ is the sampling frequency. The rate constant is yielded by minimizing the following objective function:

$$
\min \sum_{t=0}^{t_{\text {end }}}\left[(\operatorname{pct} S)_{t, \text { calc. }}-(\operatorname{pct} S)_{t, \text { pred. }}\right]^{2}
$$

where $t_{\text {end }}$ is the end time of a test sequence. The formulated cost-function can be solved analytically with log-linear transformation or by applying a suitable numerical solution strategy. In this study, the rate constant is solved with gradient descent method. 
To evaluate the industrial relevance of the rate and extent of resulfurization, the experimental setting has to fulfill the dimensional homogeneity between the crucible and the hot metal ladle. The dimensions of the systems under study are presented in Table IV. The ratio between the lab- and full-scale systems is 56.1, which is defined based on $A_{M-S} / V_{M}$ (area-volume ratio). The dimensional analysis yields that corresponding masses of hot metal $(80,000 \mathrm{~kg})$ and slag $(1200 \mathrm{~kg})$ for laboratory-scale experiments are $452.2 \mathrm{~g}$ and $6.78 \mathrm{~g}$, respectively.

Although $\mathrm{Na}_{2} \mathrm{O}$ is a strong desulfurizer, the tendency for evaporation complicates the system dynamics. According to the thermodynamic calculations of Taskinen and Janke, ${ }^{[49]}$ it is evident that in the presence of hot metal saturated with carbon, the stable form of $\mathrm{Na}_{2} \mathrm{CO}_{3}$ is $\mathrm{Na}$ in a gaseous form. ${ }^{[49]}$ However, as suggested by $\mathrm{Kim}$ et al., ${ }^{[50]}$ in the presence of $\mathrm{SiO}_{2}$, $\mathrm{Na}_{2} \mathrm{CO}_{3}$ is thermodynamically favored to decompose into $\mathrm{Na}_{2} \mathrm{SiO}_{3}$ and only a small fraction of initial $\mathrm{Na}_{2} \mathrm{CO}_{3}$ is decomposed into $\mathrm{Na}$-gas if no carbon is available for the reaction, which is consistent with the results of Pak et al. ${ }^{[32]}$ In addition to this, as the rate of evaporation is controlled by either the rate of mass transfer or chemical reaction, the effect $\mathrm{Na}_{2} \mathrm{O}$-loss on the sulfide capacity is rather small, but assumedly not negligible. ${ }^{[2,3,51,52]}$

The evaporation rate of $\mathrm{Na}_{2} \mathrm{O}$ from the slag in the presence of carbon was studied by $\mathrm{Li}$ et al. ${ }^{[51]}$ in temperatures between $1300{ }^{\circ} \mathrm{C} \quad(1573.15 \mathrm{~K})$ and $1500{ }^{\circ} \mathrm{C}(1773.15 \mathrm{~K})$. The authors suggest that the rate-limiting step for decomposition is the rate of chemical reaction at the interface or the rate of mass transfer of carbon to the interface. The authors proposed that the evaporation reaction follows the first-order reaction kinetic and determined the activation energy of the chemical reaction controlled step to be approximately $150 \mathrm{~kJ} / \mathrm{mol}^{[51]}$ Based on the extrapolation of their results, the apparent rate constant for the chemical reaction controlled step in $1350{ }^{\circ} \mathrm{C}$ $(1623.15 \mathrm{~K})$ is $k(1623.15 \mathrm{~K})=0.41 \times 10^{-5} 1 / \mathrm{s}$. Tong et al. ${ }^{[52]}$ defined the apparent rate constant in the temperature range between $1500{ }^{\circ} \mathrm{C}(1773.15 \mathrm{~K})$ and $1560{ }^{\circ} \mathrm{C}(1833.15 \mathrm{~K})$ to be $k(1833.15 \mathrm{~K})=4.02 \times$ $10^{-4} 1 / \mathrm{s} .^{[52]}$ However, the authors did not give a quantitative measure for the rate constant at $1350{ }^{\circ} \mathrm{C}$ $(1623.15 \mathrm{~K})$. Based on the assumption that the temperature dependency of the rate of reaction follows Arrhenius' kinetics, the extrapolation of their test results to the test temperature yields $k(1623.15 \mathrm{~K})=0.5 \times$ $10^{-5} 1 / \mathrm{s}$, which is in fair agreement with the rate constant extrapolated from the results of $\mathrm{Li}$ et al. ${ }^{[51]}$

\section{RESULTS AND DISCUSSION}

\section{A. Rate of Resulfurization}

The rate constant for mass transfer-controlled resulfurization was calculated based on the experimental results for each of the test series. The evolution of the sulfur content in the metal phase is presented in Figure 4. The evolution of sulfur in the metal phase appears to follow 1st-order kinetics, and the reaction seems to reach the equilibrium state relatively fast, which is in agreement with the results given in Liu et $a{ }^{[5]}$ It can also be interpreted from the figure that both the rate and extent of resulfurization are inversely proportional to the $\mathrm{Na}_{2} \mathrm{O}$ content of the slag. For this reason, it is evident that the rate and extent of resulfurization can be regulated by adding alkaline flux on the slag. These results are in qualitative agreement regarding sulfide capacity with the results of Chan and Fruehan $^{[10,11]}$ and van Niekerk and Dippenaar. ${ }^{[6]}$

The calculated time constant and apparent rate constants for the resulfurization of hot metal are presented in Table $\mathrm{V}$. It is seen that the apparent rate constants are in fair agreement with the values presented

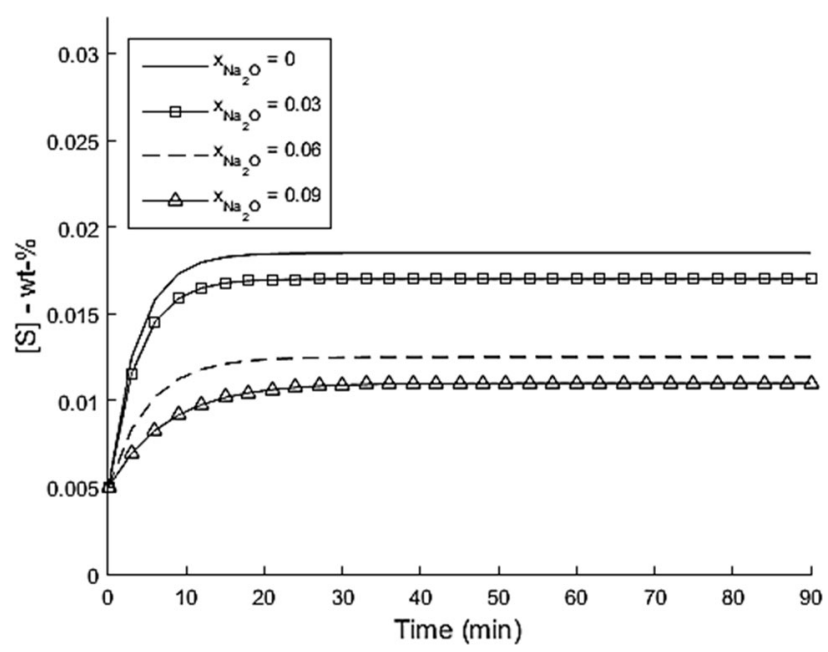

Fig. 4-The calculated evolution of sulfur in the metal phase as a function of time during the experiments.

Table V. Calculated Apparent Rate Constants Based on the Experimental Results Compared to the Corresponding Values Provided in Ref. [5]

\begin{tabular}{lccccc}
\hline Series & $k_{\text {tot }}(1 / \mathrm{s})$ & $k^{\prime}(\mathrm{m} / \mathrm{s})$ & $k^{\prime} A\left(\mathrm{~m}^{3} / \mathrm{s}\right)$ & $k^{\prime} A\left(\mathrm{~cm}^{3} / \mathrm{s}\right)$ & $k^{\prime}\left(\mathrm{m}^{\prime} / \mathrm{s}\right)^{[5]}\left(\mathrm{cm}^{3} / \mathrm{s}\right)^{[5]}$ \\
\hline 1 & 0.0045 & $2.0 \times 10^{-4}$ & $3.0 \times 10^{-7}$ & 0.30 \\
2 & 0.0044 & $1.9 \times 10^{-4}$ & $2.9 \times 10^{-7}$ & 0.29 \\
3 & 0.0033 & $1.4 \times 10^{-4}$ & $2.2 \times 10^{-7}$ & 0.22 \\
4 & 0.0022 & $9.5 \times 10^{-5}$ & $1.4 \times 10^{-7}$ & 0.14 \\
\hline
\end{tabular}




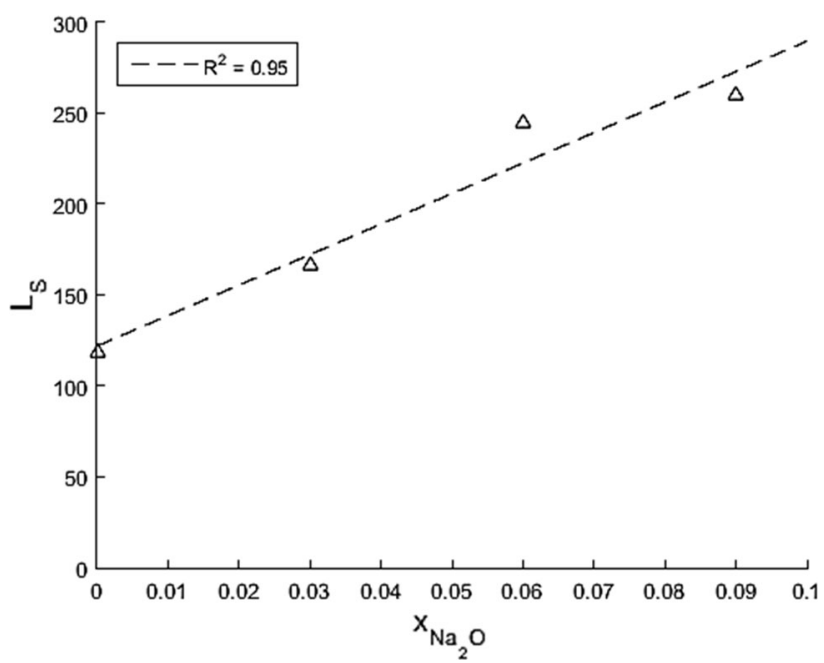

Fig. 5-The average sulfur partition ratio at time instant $t=60 \mathrm{~min}$ as a function of the molar fraction of $\mathrm{Na}_{2} \mathrm{O}$ in the slag phase.

by Liu et al., ${ }^{[5]}$ as there are significant differences in the properties of both slag and metal phases and in the temperature of the system. ${ }^{[5]}$ It is seen from the values of the apparent rate constant that the $\mathrm{Na}_{2} \mathrm{O}$ content in the slag phase not only decreases the magnitude of the thermodynamic driving force, but also assumedly affects the rate of mass transfer in the metal-slag interface due to the fact that $\mathrm{Na}_{2} \mathrm{O}$ acts as a strong flux. However, the difference between the test series 1 and 2 is practically negligible with respect to the rate of mass transfer, but remarkable when concerning the overall rate and extent of resulfurization.

In Figure 5, the effect of $\mathrm{Na}_{2} \mathrm{O}$ content on the average sulfur partition ratio is presented. The graph shows that a higher $\mathrm{Na}_{2} \mathrm{O}$ content in the slag phase results in a higher sulfur partition ratio, which is in accordance with References 2 through 4, 6, 10, 11, and 31. This being so, it is evident that the magnitude of the thermodynamic driving force can be decreased by adding an alkaline compound in the $\mathrm{xCaO} \cdot \mathrm{ySiO}_{2}$-based slag, and by that the rate of resulfurization can be regulated. Although it should be noted that as the $\mathrm{Na}_{2} \mathrm{O}$ content in the slag phase decreases as a function of time due to evaporation, the final sulfur partition ratio approaches the value corresponding to equilibrium content of $\mathrm{Na}_{2} \mathrm{O}$ in the slag phase. The mechanism behind the rate of resulfurization is discussed in more detail in the next section.

\section{B. Mechanism of Resulfurization}

To support the findings of the kinetic experiments, some thermodynamic calculations were conducted with FactSage ver. 7.2. Based on the calculations, it is evident that $\mathrm{CaO}$ and $\mathrm{CaS}$ dissolve in the liquid $x \mathrm{Na}_{2} \mathrm{O} \cdot y \mathrm{SiO}_{2}$. The distribution of sulfur between different sulfides during the thermal pre-treatment of the slag phase was evaluated with thermodynamic calculations. Figure 6 presents the effect of $\mathrm{Na}_{2} \mathrm{O}$ content on the distribution of sulfur between the different phases in molten slag, as well as the liquid phase fraction in equilibrium state in

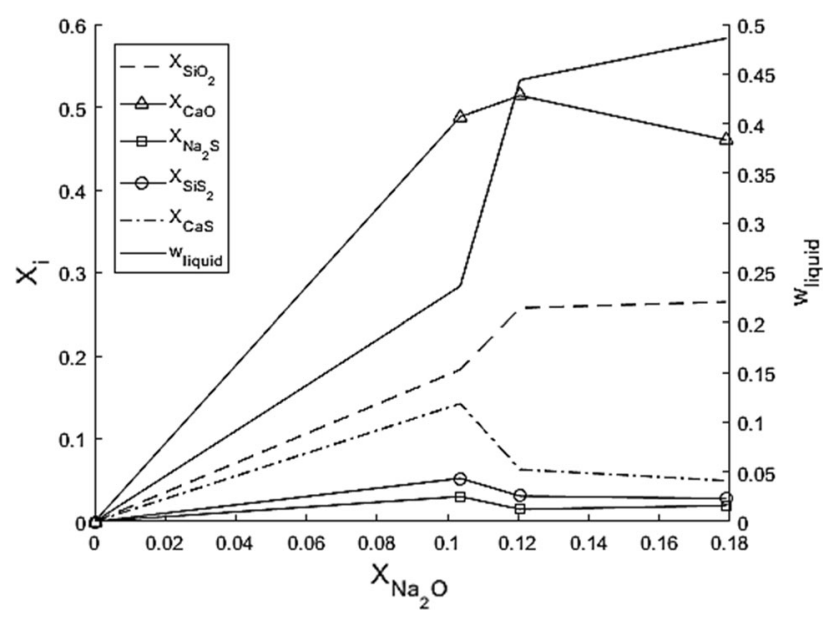

Fig. 6-Equilibrium composition of the slag phase at $1400{ }^{\circ} \mathrm{C}$ $(1673.15 \mathrm{~K})$ and $p_{\text {tot }}=1 \mathrm{~atm}$ as a function of molar fraction of $\mathrm{Na}_{2} \mathrm{O}$ in the molten slag phase.

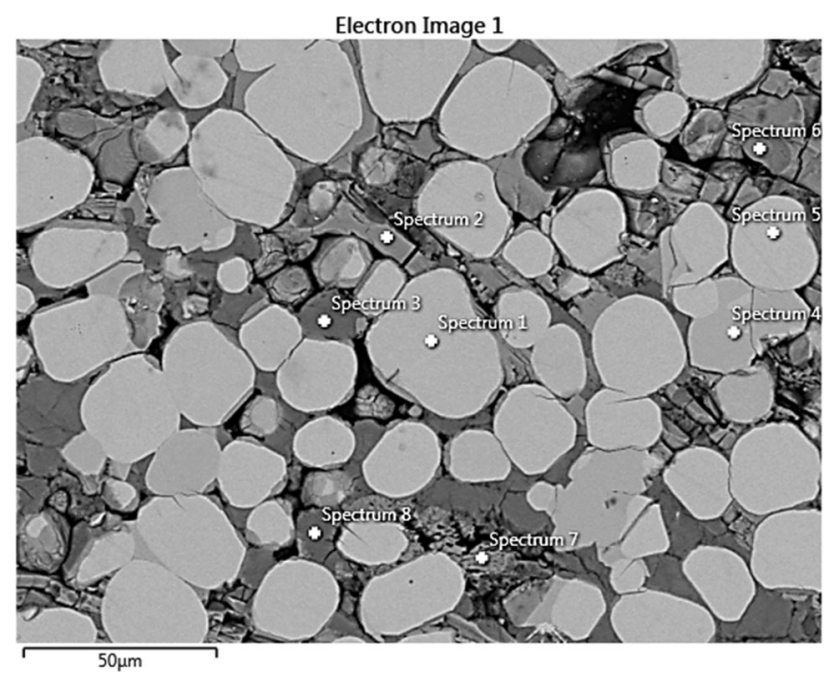

Fig. 7-Slag phase after the thermal pre-treatment, and SEM image of the corresponding slag phase.

the conditions of thermal pre-treatment. It is seen that some of the sulfur that is originally bound to $\mathrm{Ca}^{2+}$ is transformed into $\mathrm{Na}_{2} \mathrm{~S}$ during the thermal treatment in the chamber furnace. It is worth noticing that a relatively large amount of sulfur is thermodynamically favored to be bound by $\mathrm{Si}^{4+}$ to form $\mathrm{SiS}_{2}$, which could be related to the strong desulfurizing ability of the sodium-silicate phases.

Liu et $a l^{[5]}$ observed that the rate and extent of resulfurization increased with the liquid phase fraction. The results of van Niekerk and Dippenaar ${ }^{[6]}$ indicate that the increased liquid phase portion of the slag phase is not realized as an increased sulfur partition ratio, if the flux is a fluoride-based compound $\left(\mathrm{CaF}_{2}\right){ }^{[6]}$ However, Liu et al. ${ }^{[5]}$ did not consider the fact that the studied fluxes $\left(\mathrm{FeO}\right.$ and $\left.\mathrm{CaF}_{2}\right)$ both decrease the sulfide capacity according to van Nieker and Dippenaar ${ }^{[6]}$ and Schenck et $a l^{[2]}$ Thus, the rate of resulfurization increases due to the increase in thermodynamic driving 
force, which assumedly has a greater effect on the molar flux of sulfur through the metal-slag interface than the mass transfer coefficient does. By that, it is evident that the increase in the liquid phase fraction could regulate the net rate of resulfurization, but only in the case of fluxes with high sulfide capacities. Nevertheless, it can be stated that the sulfide capacity is a more dominant variable than, for example, viscosity or interfacial tension, both of which are related to the physical properties of the slag phase, when concerning the overall molar flux through the metal-slag interface.

The slag samples were analyzed using field emission scanning electron microscope (FESEM) to provide additional information on their morphology. Figure 7 shows a FESEM image of the slag phase that is taken from the polished microsection of thermally pre-treated slag. The chemical analysis of the spectrums supports the thermodynamic calculations; for example, the spectrums $3(\mathrm{Na}=13.7 \mathrm{wt}$ pct, $\mathrm{Ca}=18.1 \mathrm{wt}$ pct, $\mathrm{S}=$ 39.8 wt pct $)$ and 8 (Na $=16.8$ wt pet, $\mathrm{Ca}=$ 17.2 wt pct, $\mathrm{S}=38.5 \mathrm{wt}$ pct) correspond to a $\mathrm{Na}-\mathrm{Ca}-$ S-O-phase which indicates a co-existence of $\mathrm{Na}_{2} \mathrm{~S}$ and $\mathrm{CaS}$. A $\mathrm{CaO} / \mathrm{CaS}$ phase is found from the spectrum $2(\mathrm{Ca}=32.5 \mathrm{wt}$ pct, $\mathrm{S}=26.5 \mathrm{wt} \mathrm{pct})$. As the $x \mathrm{Na}_{2} \mathrm{O} \cdot y \mathrm{SiO}_{2}$ phases solidify as glassy phases, their existence is not observable with FESEM. The observation of the morphology of the slag reveals that the system contains a high amount of non-dissolved $\mathrm{CaO}$ $\left(\mathrm{CaO} / \mathrm{SiO}_{2}=B_{2}=5.1\right)$. It is obvious that in high temperatures such a high $\mathrm{CaO} / \mathrm{SiO}_{2}$ ratio would result in an increased sulfur partition ratio, but as the system operates at $1350{ }^{\circ} \mathrm{C}(1523 \mathrm{~K})$, the high $\mathrm{CaO}$ content does not lead to an corresponding increase in sulfide capacity, as the contact area between two solid phases is small. The low contact area would also regulate the rate of resulfurization and desulfurization reactions between the solid slag and hot metal. Based on this, it can be said that as the parameters of the existing models are identified for the thoroughly molten slag, they assumedly do not describe the changes in the sulfide capacity with sufficient accuracy, especially in a situation where the $\mathrm{CaO}$ content is well above the saturation limit.

It is seen that the slag phase has melted during the pre-treatment, which indicates the fluxing effect of $\mathrm{Na}_{2} \mathrm{O}$. A more careful investigation of the slag phase with FESEM shows that the CaS has been dissolved in the $\mathrm{Na}_{2} \mathrm{O}-\mathrm{Na}_{2} \mathrm{CO}_{3}$ melt, and formed a mixed $\mathrm{Ca}-\mathrm{Na}-\mathrm{O}-\mathrm{S}$ phase. The formation of the aforementioned phase is supported by the thermodynamic calculations, which indicate the co-existence of $\mathrm{Na}_{2} \mathrm{~S}$ and $\mathrm{CaS}$ in the slag phase. Thus, it is evident that $\mathrm{Na}^{+}$has a high affinity for sulfur, which is consistent with various authors. ${ }^{[2-4,6,10,11,13,30,32]}$

The differences in the rate of mass transfer between the varying flux contents can be explained with the morphology of the slag. The increase in the liquid phase fraction gives the slag a more homogeneous form due to the increased fraction of dissolved sulfides and oxides. A more accurate inspection of individual samples in the case of test series 1 (solid slag) reveals that the resulfurization could take place between individual particles, as the rate of resulfurization is significantly higher than in the case of partially liquid slag. From a mass transfer point of view, a slag containing a high amount of non-dissolved $\mathrm{CaO}-\mathrm{CaS}$ particles is more similar to a packed bed of particles than a homogeneous slag layer. Consequently, the rate-controlling mechanism is dependent on the morphology of the slag.

\section{Effect of Sulfide Capacity of the Slag}

To evaluate the effect of composition and temperature on the sulfide capacity of the $\mathrm{CaO}-\mathrm{SiO}_{2}-\mathrm{Na}_{2} \mathrm{O}$ system, the results of this study were combined with the data given in References 6, 10, 11, and 31, all of which make use of the metal-slag equilibrium method in the determination of the sulfide capacity. The combined data include a total of 100 data points, and cover the compositional range from $\mathrm{Na}_{2} \mathrm{O}-\mathrm{SiO}_{2}$ binary systems to ternary systems that are saturated with $\mathrm{CaO}$ and furthermore to system that contain undissolved $\mathrm{CaO}$ particles. The measurements have been conducted in a temperature range of $1200{ }^{\circ} \mathrm{C}$ and $1400{ }^{\circ} \mathrm{C}(1473.15 \mathrm{~K}$ and $1673.15 \mathrm{~K})$.

The measured sulfur capacity was predicted using the proposed ANN as well as with two other modeling approaches: a simple MLR model and a MLR model with the quadratic predictor (KTH-type model). It should be noted that variables for the MLR and ANN were selected manually with the forward selection procedure as explained in Section II-C, whereas the form of the KTH-type model was identified based on the descriptions given in References 14 through 17 . The resulting model for the sulfide capacity of the slag is given as

$$
\begin{aligned}
\log _{10} C_{\mathrm{S}, \text { eff. }}= & b_{0}+b_{1} \log _{10} a_{[\mathrm{O}]}^{\mathrm{H}}+b_{2} \frac{\left(\mathrm{Na}_{2} \mathrm{O}\right)}{\left(\mathrm{SiO}_{2}\right)} \\
& +b_{3} \log _{10}(\mathrm{CaO})+b_{4} \frac{1}{T} .
\end{aligned}
$$

Inserting the expression of the sulfide capacity to the definition of the sulfur partition ratio yields the following expression:

$$
\begin{aligned}
\log _{10} L_{\mathrm{S}}= & b_{0}+\left(b_{1}-1\right) \log _{10} a_{[\mathrm{O}]}^{\mathrm{H}}+b_{2} \frac{\left(\mathrm{Na}_{2} \mathrm{O}\right)}{\left(\mathrm{SiO}_{2}\right)} \\
& +b_{3} \log _{10}(\mathrm{CaO})+\left(\frac{b_{4}-935}{T}\right)-\log _{10} f_{[\mathrm{S}]} \\
& +1.375 .
\end{aligned}
$$

The architecture of the ANN model was kept as parsimonious as possible keeping in mind training performance and generalizability of the network. Hence, the resulting network constitutes of five input variables $\left(X_{\mathrm{Na}_{2} \mathrm{O}}, X_{\mathrm{CaO}}, X_{\mathrm{SiO}_{2}}, \frac{1}{T}\right.$ and $\left.a_{[\mathrm{O}]}^{\mathrm{H}}\right)$, three hidden neurons with sigmoidal activation functions and an output neuron with a linear activation function. The training of the ANN was performed with the algorithm proposed in Section II-C. To improve the convergence of the training algorithm, the experimental data were treated with zero-mean and unit-variance normalizations. The 
Table VI. Training and External Validation of the Modeling Approaches

\begin{tabular}{lccc}
\hline & ANN & MLR & KTH-Type Model* \\
\hline$R^{2}$-Training & 0.84 & 0.75 & 0.78 \\
MAE [for $\log _{10}\left(C_{\mathrm{S}}\right)$ ]-Training & 0.15 & 0.19 & 0.17 \\
$R^{2}$-External Validation & 0.89 & 0.68 & 0.77 \\
MAE [for $\log _{10}\left(C_{\mathrm{S}}\right)$ ]-External Validation & 0.12 & 0.25 & 0.20 \\
\hline
\end{tabular}

*Fitted to studied data with Moore-Penrose inversion.

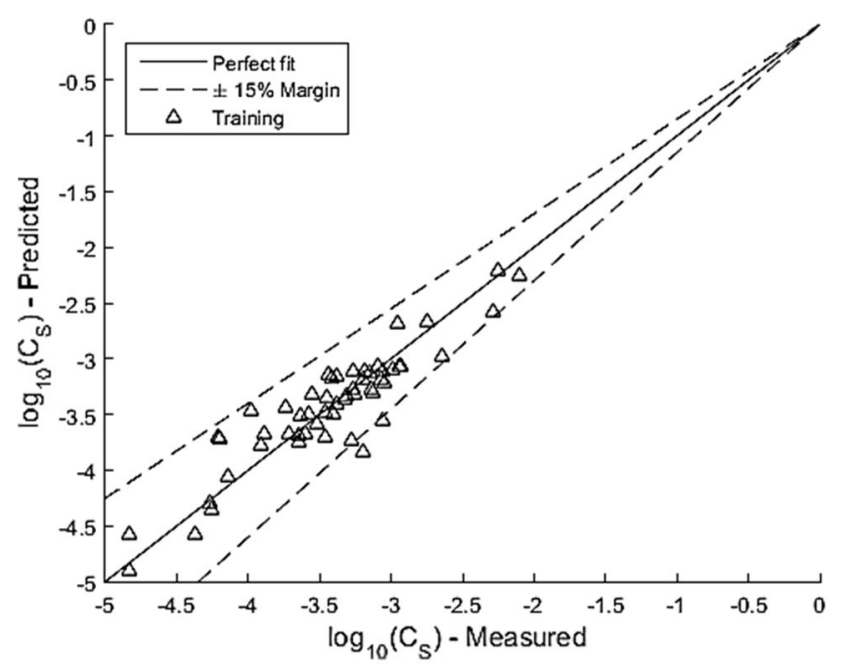

(a)

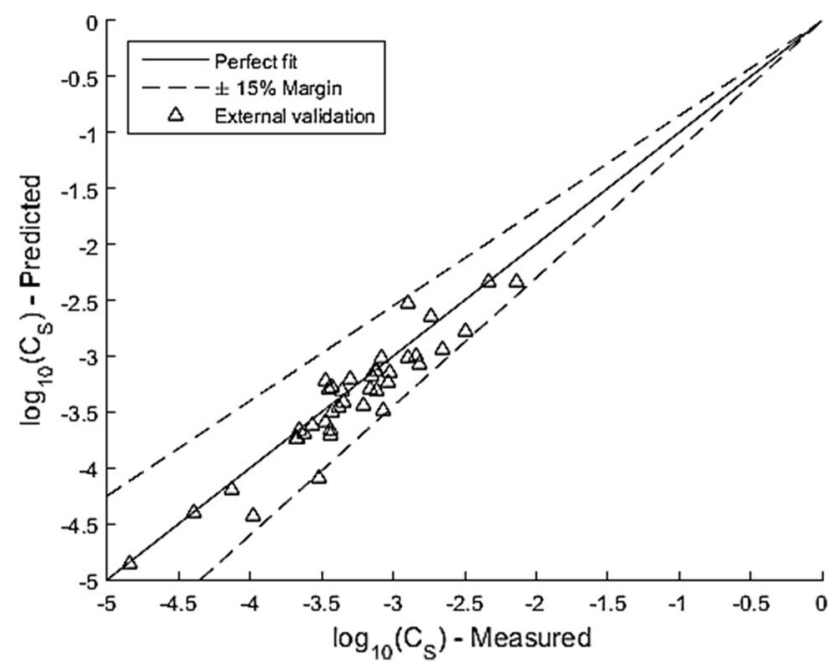

(b)

Fig. 8-(a) Training and (b) external validation data sets predicted with ANN.

Table VII. Quantitative Measure of Predictive Power of Existing Sulfide Capacity Models and Their Applicability in the Prediction of Sulfur Partition Ratios Between Hot Metal and $\mathrm{Na}_{2} \mathrm{O}-\mathrm{SiO}_{2}$ and $\mathrm{CaO}-\mathrm{SiO}_{2}-\mathrm{Na}_{2} \mathrm{O}$ Slag Systems

\begin{tabular}{|c|c|c|}
\hline Study or Method & $R^{2}$ & MAE $\left[\right.$ for $\left.\log _{10}\left(L_{\mathrm{S}}\right)\right]$ \\
\hline Sosinsky and Sommerville ${ }^{[8]}$ & 0.39 & 1.13 \\
\hline Young et al. ${ }^{[7]}$ & 0.29 & 1.16 \\
\hline Zhang et al..$^{[26]}$ & 0.40 & 0.96 \\
\hline van Niekerk and Dippenaar ${ }^{[6]}$ & 0.26 & 0.50 \\
\hline Chan and Fruehan ${ }^{[10,11]}$ & 0.40 & 0.56 \\
\hline KTH-type Model* & 0.81 & 0.18 \\
\hline KTH-type Model ${ }^{[17] * *}$ & 0.61 & 0.29 \\
\hline This Work-MLR* & 0.75 & 0.21 \\
\hline This Work-ANN*** & 0.88 & 0.15 \\
\hline
\end{tabular}

*Fitted to studied data with Moore-Penrose Inversion.

**Calculated with the parameters given in Ref. [17] and with the parameters identified with GA.

***Trained to studied data with the algorithm proposed in Section II-C.

measures of the fit for all the model types are given in Table VI. The cross-validated training result of the neural network is presented in Figure 8. The comparative summary of the predictive power of the selected models for sulfide capacity as well as the modeling approaches proposed in this study is presented in Table VII.

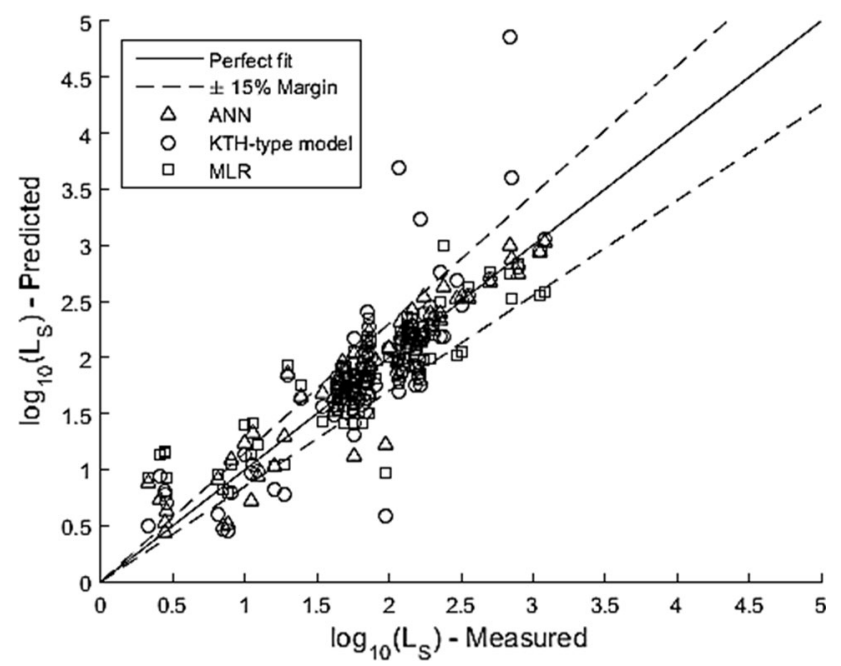

Fig. 9 - Comparison of the sulfide capacity models in the prediction of the sulfur partition ratio.

A comparative illustration of the models fitted in this study is presented in Figure 9. It is seen from the figure that all the suggested model types are capable of explaining a large fraction of the total variance in the sulfur partition ratio. However, it is seen from the figure and interpretable from the table that the ANN approach outperforms the other models. This is easily 


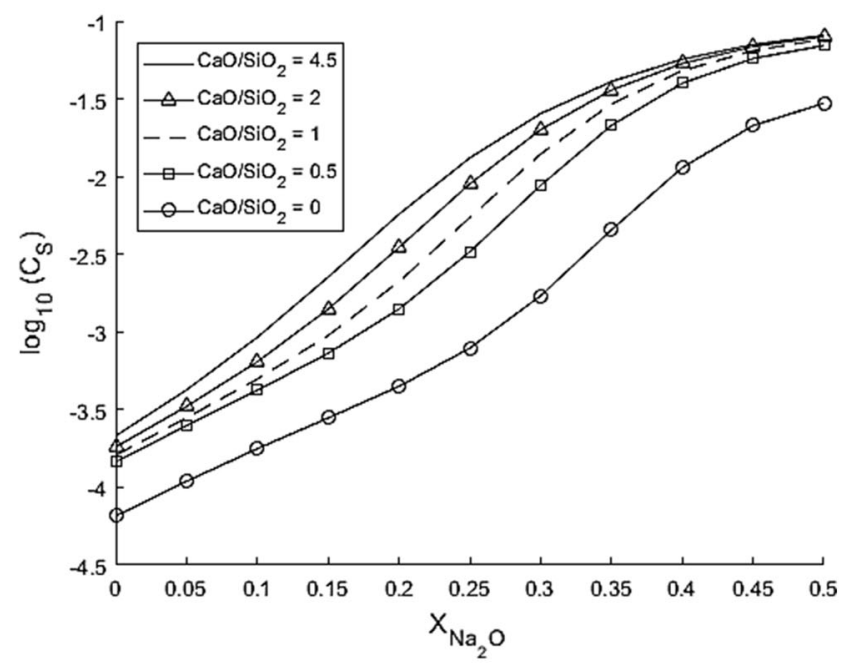

(a)

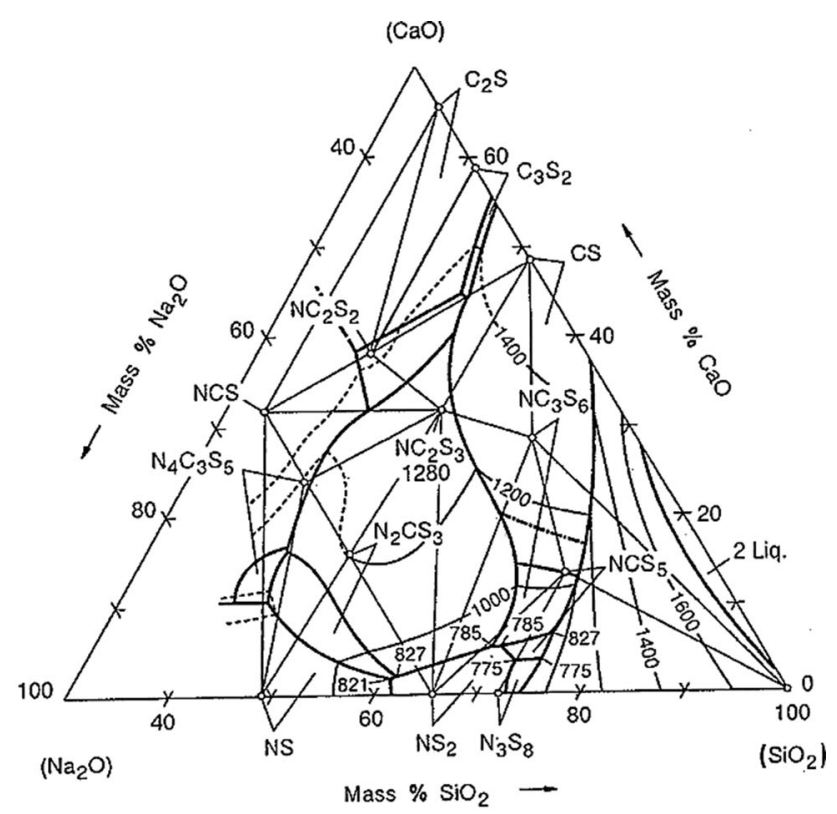

(b)

Fig. 10 - (a) Sulfide capacity as a function of molar fraction of $\mathrm{Na}_{2} \mathrm{O}$ and $\mathrm{CaO} / \mathrm{SiO}_{2}$ ratio of the slag phase predicted with the selected $\mathrm{ANN}$ $\left(T=1623.15 \mathrm{~K}\right.$ and $\left.a_{[\mathrm{O}]}^{\mathrm{H}}=10^{-4}\right)$. (b) Liquidus projection of the $\mathrm{CaO}-\mathrm{SiO}_{2}-\mathrm{Na}_{2} \mathrm{O}$ slag system. ${ }^{[56]}$

explained with the fundamental differences in the prediction model types; a non-linear approach explains better the highly non-linear nature of the effect of slag composition and system conditions on the sulfide capacity. From Table VII it can be also seen that the models fitted for the $\mathrm{Na}_{2} \mathrm{O}-\mathrm{SiO}_{2}$ binary system ${ }^{[10,11]}$ do not describe the changes in the sulfide capacity of the $\mathrm{CaO}-\mathrm{SiO}_{2}-\mathrm{Na}_{2} \mathrm{O}$ system, and it is evident that the model given by van Niekerk and Dippenaar ${ }^{[6]}$ gives reasonable results only when $\mathrm{CaO}$ content is between 30 and $45 \mathrm{wt}$ pct. When analyzing the modeling results in more detail, it can be observed that the values predicted with the models presented by Chan and Fruehan ${ }^{[10,11]}$ are highly overestimated $(\mathrm{MAE}=0.58)$, whereas the models of Sosinsky and Somerville ${ }^{[8]}$ and Young et al. ${ }^{[7]}$ underestimate the sulfide capacities. The most consistent results with the modeling approaches presented in this study are acquired with the KTH-type model. However, as was presumed from the results of the previous studies, ${ }^{[1-17]}$ the data set is simply not adequate to reveal all the interactions that are included in the model. Also it is evident that the parameters given in literature ${ }^{[17]}$ are not suitable of predicting the sulfide capacity for high $\mathrm{CaO}$ contents.

In relatively low temperatures and in the case of slags with high $\mathrm{CaO} / \mathrm{SiO}_{2}$ ratios, the slag phase contains a significant amount of non-dissolved $\mathrm{CaO}$, which does not take part in desulfurization. Thus, the high $\mathrm{CaO}$ content ratio is not realized as an increased sulfide capacity because the nominal number of $\mathrm{Ca}^{2+}$-cations is significantly larger than the number of cations that actually take part in the reactions. This is also consistent with the findings of Vargas-Ramirez et al. ${ }^{[30]}$ This particular matter is also observable from Figure 10, which shows that the sulfide capacity of a ternary $\mathrm{CaO}-\mathrm{SiO}_{2}-\mathrm{Na}_{2} \mathrm{O}$ slag system is higher than the sulfide capacity of a binary $\mathrm{Na}_{2} \mathrm{O}-\mathrm{SiO}_{2}$. However, it is observable that in relatively low temperatures $1350{ }^{\circ} \mathrm{C}$ $(1623.15 \mathrm{~K})$, the effect of $\mathrm{CaO}$ content is more prominent with contents below a typical saturation limit in the system, which is $\mathrm{B}_{2} \approx 1$ under the given conditions. This is qualitatively consistent with the results of van Niekerk and Dippenaar, ${ }^{[6]}$ who proposed a linear dependency between the sulfur partition ratio and $\mathrm{CaO} / \mathrm{Na}_{2} \mathrm{O}$ ratio. However, van Niekerk and Dippenaar suggested that the sulfur partition ratio decreases with the increase in the $\mathrm{CaO} / \mathrm{Na}_{2} \mathrm{O}$ ratio. However, it is likely that this conclusion holds only in certain compositional areas, namely, in the case where $\mathrm{Na}_{2} \mathrm{O}$ contents in the slag are low.

The results of Pak et al. ${ }^{[32]}$ imply that the activity of $\mathrm{Na}_{2} \mathrm{O}$ is highly dependent on the activity of $\mathrm{SiO}_{2}$. Especially with high $\mathrm{Na}_{2} \mathrm{O}$ contents, it is seen that there is a complex interaction between the sulfide capacity and the interaction of $\mathrm{Na}_{2} \mathrm{O}$ and $\mathrm{CaO} / \mathrm{SiO}_{2}$. The cross-interaction of $\mathrm{Na}_{2} \mathrm{O}$ and $\mathrm{SiO}_{2}$ is seen in Figure 10(a); when the $\mathrm{CaO} / \mathrm{SiO}_{2}$ ratio is kept constant and the fraction of $\mathrm{Na}_{2} \mathrm{O}$ increases, the $\mathrm{SiO}_{2}$ content and thus the activity of $\mathrm{SiO}_{2}$ decrease. This being so, according to the modeling results, the increase in the $\mathrm{CaO} / \mathrm{SiO}_{2}$ ratio results as a logistic increase in the sulfide capacity in the certain compositional areas an in low temperatures. From this it can be further deduced that the contribution of the non-dissolved $\mathrm{CaO}$ particles to desulfurization are lower than the contribution of dissolved $\mathrm{CaO}$. This deduction is supported by the ternary phase 


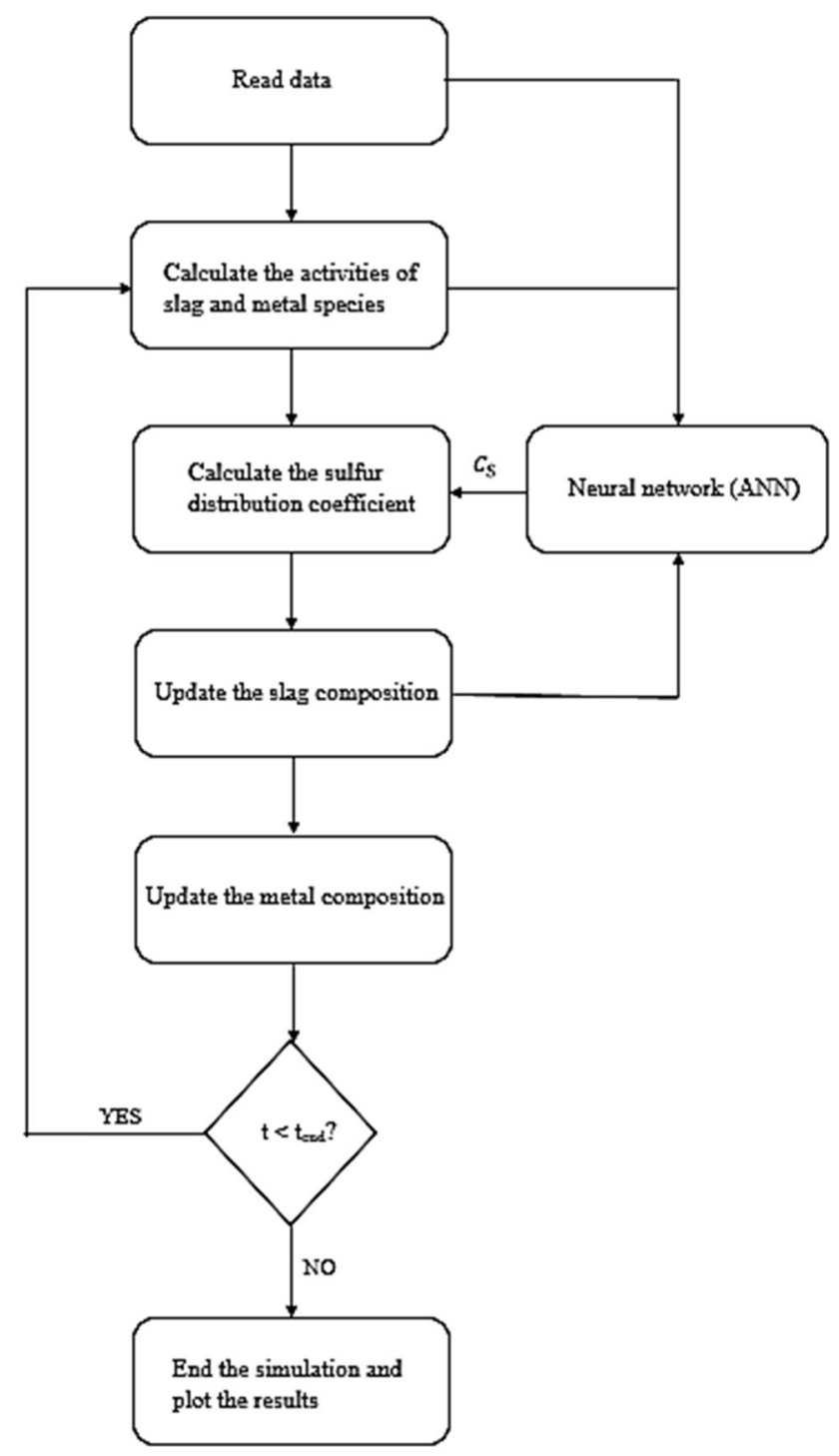

Fig. 11-Flowchart of the resulfurization model.

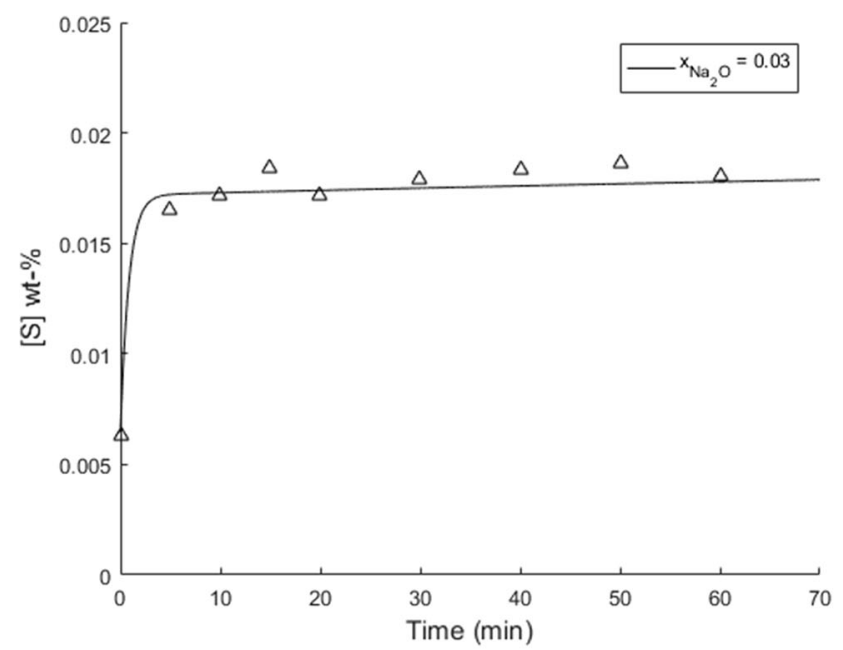

(a) diagram that is presented in Figure 10(b). However, the magnitude of the interaction should be critically evaluated due to the interpolation properties of the ANN and errors related to the experimental setting and to the feature generation procedure.

\section{Kinetic Simulations}

To evaluate the industrial relevance, the kinetic simulations were carried out with the model presented in Section II. The numerical solution of the differential equations is conducted with 4th order Runge-Kutta method, which was originally formulated by Runge. ${ }^{[57]}$ The flowchart of the calculation procedure is illustrated in Figure 11.

From the results of the simulations, it is seen that the metal-slag system reaches an apparent thermodynamic equilibrium very fast, but the resulfurization reaction could carry on due to the dynamics of the slag phase. When comparing the rate curves between $3.2 \mathrm{wt}$ pct and 10.1 wt pet $\mathrm{Na}_{2} \mathrm{O}$ contents, it is seen that the evaporation of $\mathrm{Na}_{2} \mathrm{O}$ decreases the sulfide capacity of the slag, which results in the apparent equilibrium state evolving dynamically. The dynamics and extent of resulfurization predicted by the proposed reaction model are illustrated in Figure 12. It is seen that the model is capable of predicting the extent of resulfurization with reasonable accuracy $R^{2}=0.77$ and MAE $=0.0015 \mathrm{wt}$ pct.

If the assumption of the dimensional similarity is drawn, the evolution of sulfur content in the metal phase can be evaluated in the case of the industrial scale process. The simulation results are presented in Figure 13. It is seen that in the industrial scale, the rate of mass transfer has a more prominent effect on the net rate of resulfurization, but the differences between the series can be explained with the thermodynamic driving force. When observing the curves, it can be said that the resulfurization of hot metal is a technically relevant phenomenon under conditions of this study.

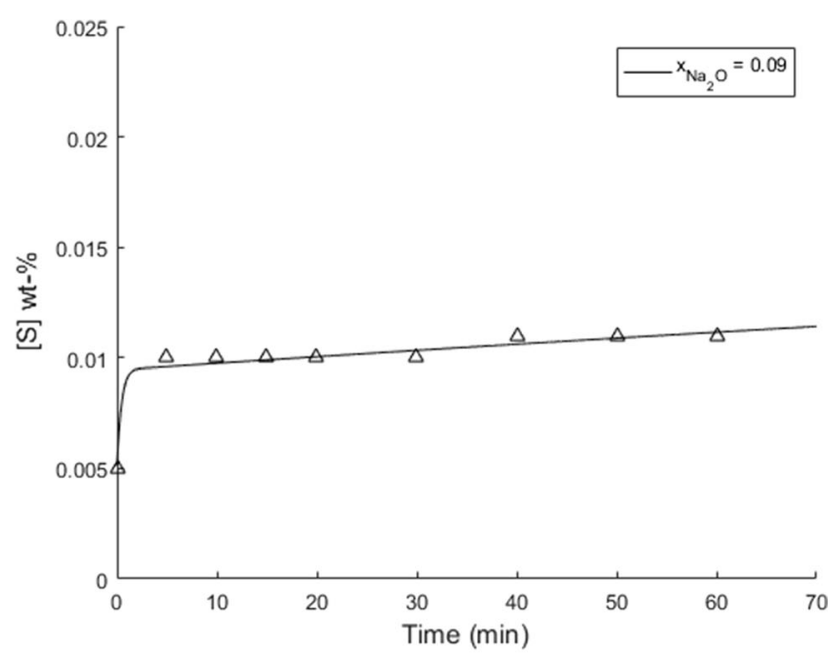

(b)

Fig. 12-Evolution of sulfur content as a function of time in hot metal. (a) $X_{\mathrm{Na}_{2} \mathrm{O}}=0.03$, (b) $\mathrm{X}_{\mathrm{Na}_{2} \mathrm{O}}=0.09$. 


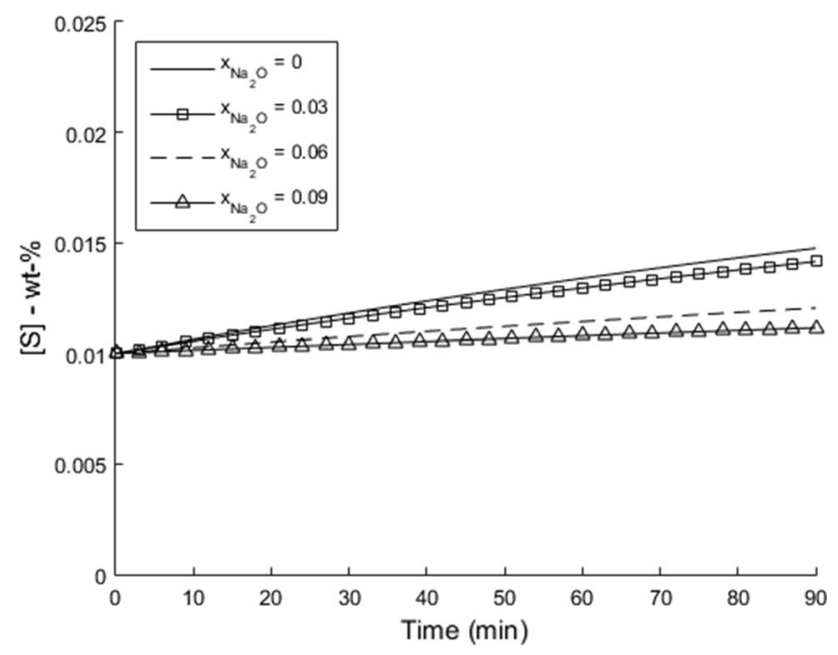

Fig. 13-The calculated evolution of sulfur in the metal phase as a function of time with the industrial scale dimensions presented in Table IV.

It should be noted that assumedly there are some fundamental differences between the industrial and laboratory-scale systems. As the slag phase of the industrial hot metal desulfurization forms during the injection, the composition of it is highly dependent on the dynamics of the desulfurization. As the sulfur content of the individual particles is significantly smaller at the end of injection, the sulfur content at the metal-slag interface is not necessarily as high as $3.5 \mathrm{wt}$ pct. In addition, due to heterogeneous structure of the slag, the complex morphology of the industrial hot metal desulfurization slag increases the complexity of the reaction mechanism. These implications are in agreement with the findings of Condo. ${ }^{[58]}$

\section{CONCLUSIONS}

The main results of this study can be summarized as follows:

1. Resulfurization of hot metal was found to occur under experimental conditions mimicking those after hot metal desulfurization using lance injection in a ladle. It is suggested that this is due to the fact that the sulfur removal capability of the slag is typically lower than that of the desulfurization reagent. The resulfurization reaction is driven by a thermodynamic driving force created by the difference between the sulfur content in the bulk and the sulfur content in equilibrium with the slag.

2. The rate of resulfurization can be regulated by increasing the $\mathrm{Na}_{2} \mathrm{O}$ content in the $\mathrm{CaO}-\mathrm{SiO}_{2}-\mathrm{Na}_{2} \mathrm{O}$ system. The effect of $\mathrm{CaO}$ on the sulfide capacity was found to be much higher in contents well below or near the saturation limit, which implies that the undissolved particles provide only a limited contribution to desulfurization.

3. The morphology of the slag phase determines the rate-controlling step. However, in these concentra- tion areas, the thermodynamic driving force has a more prominent effect on the net rate than the rate of mass transfer, when the emulsification of small CaS particles in the metal phase has not been taken into account. When increasing the liquid phase fraction of the slag, the rate of resulfurization could decrease due to increased dissolution of sulfides in the slag phase.

4. The optical basicity of the slag does not seem to be a suitable predictor in predicting the sulfide capacity $\mathrm{CaO}-\mathrm{SiO}_{2}-\mathrm{Na}_{2} \mathrm{O}$ slag system, especially in low temperatures where the solubility of $\mathrm{CaO}$ is low. This could be associated with complex non-linear interactions of the system under study. Especially, as the composition and morphology of the slag is determined by the injection scheme. The neural network model for sulfide capacity would be beneficial to extend in systems with higher-order systems, and thus could be applied in the prediction of other processes as well.

\section{ACKNOWLEDGMENTS}

Open access funding provided by University of Oulu including Oulu University Hospital. This work was conducted within the Symbiosis of Metal Production and Nature (SYMMET) research program, which is funded by Business Finland. The financial support from Technology Industries of Finland Centennial Foundation as well as Finnish Cultural Foundation is also acknowledged. The authors would like to thank Mr. Riku Mattila for technical aid.

\section{OPEN ACCESS}

This article is distributed under the terms of the Creative Commons Attribution 4.0 International License (http://creativecommons.org/licenses/by/4.0/), which permits unrestricted use, distribution, and reproduction in any medium, provided you give appropriate credit to the original author(s) and the source, provide a link to the Creative Commons license, and indicate if changes were made.

\section{NOMENCLATURE}

$\begin{array}{ll}A & \text { Area }\left(\mathrm{m}^{2}\right) \\ b_{i} & \text { Regression coefficient for a variable } i(-) \\ C_{\mathrm{S}} & \begin{array}{l}\text { Sulfide capacity determined from gas-slag } \\ \text { equilibrium }(-)\end{array} \\ C_{\mathrm{S}}^{\prime} & \begin{array}{l}\text { Sulfide capacity determined from metal-slag } \\ \text { equilibrium }(-)\end{array} \\ D & \text { Diffusion coefficient }\left(\mathrm{m}^{2} / \mathrm{s}\right) \\ f & \text { Henrian activity coefficient }(-) \\ K & \text { Equilibrium constant }(-) \\ k_{\mathrm{tot}} & \text { Rate constant of the permanent contact } \\ & \text { reaction }(1 / \mathrm{s}) \\ L_{\mathrm{S}} & \text { Sulfur distribution coefficient }(-)\end{array}$


$m \quad$ Mass of a phase $(\mathrm{kg})$

$R \quad$ Universal gas constant $(8.3145 \mathrm{~J} /(\mathrm{K} \cdot \mathrm{mol}))$

$R^{2} \quad$ Coefficient of determination (-)

$T \quad$ Temperature (K)

$t \quad$ Time (s)

$t_{\max } \quad$ Experimental time (s)

$V \quad$ Volume $\left(\mathrm{m}^{3}\right)$

$x_{i} \quad$ Molar fraction of a compound $i(-)$

$\hat{X}_{i} \quad$ Cation fraction of a compound $i(-)$

$X \quad$ Data-matrix (-)

$y \quad$ Output variable (-)

$\hat{y} \quad$ Predicted output variable (-)

$w \quad$ Mass fraction (-)

$\beta \quad$ Mass transfer coefficient $(\mathrm{m} / \mathrm{s})$

$\delta \quad$ Length of the diffusion boundary layer (m)

$\rho^{*} \quad$ Density ratio between slag and metal $\left(\mathrm{kg} / \mathrm{m}^{3}\right)$

$\Lambda \quad$ Optical basicity (-)

$\gamma \quad$ Raoultian activity coefficient (-)

[ ] Species dissolved in hot metal (-)

() Species in slag phase (-)

\{ $\} \quad$ Species in gas phase (-)

〈〉 Solid species (-)

ANN Artificial neural network (-)

MLR Multivariable linear regression

MAE Mean absolute error of prediction (-)

SSE Sum of squared errors (-)

\section{REFERENCES}

1. U. Pal and B. Patil: Ironmak. Steelmak., 1986, vol. 13, pp. 294 300.

2. H. Schenck, E. Steinmetz, and Z. Yun: Arch. Eisenhüttenwes., 1969, vol. 40, pp. 759-65.

3. J. Choi, D. Kim, and H. Lee: ISIJ Int., 2001, vol. 41, pp. 216-24.

4. Z. Tong, J. Qiao, and J. Xiyuan: ISIJ Int., 2017, vol. 57, pp. 24553.

5. C. Liu, F. Huang, X. Wang, and G. Yang: Metall. Res. Technol., 2015 , vol. 112, p. 8 .

6. W. van Niekerk and R. Dippenaar: ISIJ Int., 1993, vol. 33, pp. 5965.

7. R. Young, J. Duffy, G. Hassall, and Z. Xu: Ironmak. Steelmak., 1992, vol. 19, pp. 201-19.

8. D. Sosinsky and I. Sommerville: Metall. Mater. Trans. B, 1986, vol. 17B, pp. 331-37.

9. R.G. Reddy and M. Blander: Metall. Mater. Trans. B, 1987, vol. 18 B, pp. 591-96.

10. A.H. Chan and R.J. Fruehan: Metall. Mater. Trans. B, 1986, vol. 17B, pp. 491-96.

11. A.H. Chan and R.J. Fruehan: Metall. Mater. Trans. B, 1989, vol. 20B, pp. 71-76.

12. R.G. Reddy and M. Blander: Metall. Mater. Trans. B, 1989, vol. 20B, pp. 137-40.

13. Kunisada and Iwai: ISIJ Int., 1993, vol. 33, pp. 43-47.

14. D. Sichen, R. Nilsson, and S. Seetharam: Verlag Stahleisen, 1995, vol. 11 , pp. $458-62$.

15. R. Nilsson, D. Sichen, and S. Seetharam: Scand. J. Metall., 1996, vol. 25, pp. 128-34.

16. M. Nzotta, D. Sichen, and S. Seetharaman: ISIJ Int., 1998, vol. 11, pp. 1170-79.

17. M. Nzotta, D. Sichen, and S. Seetharaman: ISIJ Int., 1999, vol. 39 , pp. 657-63.

18. A. Shankar, M. Görnerup, A.K. Lahiri, and S. Seetharaman: Metall. Mater. Trans. B, 2006, vol. 37B, pp. 941-47.

19. Y. Taniguchi, N. Sano, and S. Seetharaman: ISIJ Int., 2009, vol. 49 , pp. $156-63$.

20. L. Wang and S. Seetharaman: Metall. Mater. Trans. B, 2010, vol. 41B, pp. 367-73.
21. C.-B. Shi, X.-M. Yang, J.-S. Jiao, C. Li, and H.-J. Guo: ISIJ Int., 2010, vol. 50, pp. 1362-72.

22. X. Yang, J. Li, M. Zhang, G. Chai, and J. Zhang: Metall. Mater. Trans. B, 2014, vol. 45B, pp. 2118-37.

23. Y. Gao, Q. Liu, and L. Bian: Metall. Mater. Trans. B, 2012, vol. 43B, pp. 229-32.

24. Y. Taniguchi, L. Wang, N. Sano, and S. Seetharaman: Metall. Mater. Trans. B, 2012, vol. 43B, pp. 477-84.

25. J.H. Park and G.H. Park: ISIJ Int., 2012, vol. 52, pp. 764-69.

26. G. Zhang, K. Chou, and U. Pal: ISIJ Int., 2013, vol. 53, pp. 76167.

27. B. Derin, M. Suzuki, and T. Tanaka: ISIJ Int., 2010, vol. 50, pp. 1059-63.

28. A. Ma, S. Moshtagel, and K. Chattopadhyay: ISIJ Int., 2017, vol. 57 , pp. $1-9$.

29. A. Ma, S. Chatterjee, A. Maity, K. Chattopadhyay, and A. Mukherjee: Proceedings of the 2018 AISTech-Iron and Steel Technology conference.

30. M. Vargas-Ramirez, A. Romeiro-Serrano, R. Morales, M. Angeles-Hernandez, F. Chavez-Alcala, and J. Castro-Allerano: Steel Res., 2001, vol. 72, pp. 173-81.

31. R. Inoue and H. Suito: Trans. Iron Steel Inst. Jpn., 1982, vol. 22, pp. 514-23.

32. J. Pak, K. Ito, and R. Fruehan: ISIJ Int., 1989, vol. 29, pp. 318-23.

33. A. Bulsari and H. Saxén: Neurocomputing, 1991, vol. 3, pp. 125-33.

34. J. Pollard, M. Broussard, D. Garrison, and K. San: Comput. Chem. Eng., 1992, vol. 16, pp. 253-70.

35. H. Saxén and F. Pettersson: ISIJ Int., 2007, vol. 47, pp. 1732-37.

36. G. Cybenko: Math. Control Signals Syst., 1989, vol. 2, pp. 303-14.

37. K. Hornik, M. Stinchcombe, and H. White: Neural Netw., 1989, vol. 2, pp. 359-66.

38. M. Hagan and M. Menhaj: IEEE Trans. Neural Netw., 1994, vol. 5 , pp. 989-93.

39. J. Nelder and R. Mead: Comput. J., 1965, vol. 7, pp. 308-13.

40. S. Asadi, J. Shahrabi, P. Abbaszadeh, and S. Tabanmehr: Neurocomputing, 2013, vol. 121, pp. 470-80.

41. J. Kennedy and R. Eberhart, Proceedings of the 1995 IEEE International Conference on Neural Networks, pp. 1942-1948.

42. Y. Kao and E. Zahara: Appl. Soft Comput., 2008, vol. 8, pp. 849-57.

43. Y. Marinakis and M. Marinakis: Expert Syst. Appl., 2010, vol. 37, pp. $1446-55$.

44. MathWorks: Deep Learning Toolbox Sample Data Sets for Shallow Networks: https://se.mathworks.com/help/deeplearning/g s/deep-learning-toolbox-sample-data-sets.html. Accessed 23 November 2018.

45. F. Oeters: Metallurgy of Steelmaking, Verlag Stahlheisen mbH, Düsseldorf, Germany, 1994.

46. E. Turkdogan: Fundamentals Of Steelmaking, London: Institute of Materials, Great-Brittain, London, 1996.

47. G. Sigworth and J. Elliott: Met. Sci., 1974, vol. 8, pp. 298-310.

48. S. Ban-Ya: ISIJ Int., 1993, vol. 33, pp. 2-11.

49. P. Taskinen and D. Janke: Arch. Eisenhüttenwes., 1983, vol. 54, pp. 175-80.

50. J. Kim, Y. Lee, and H. Lee: ISIJ Int., 2001, vol. 41, pp. 116-23.

51. M. Li, T. Utigard, and M. Barati: Metall. Mater. Trans. B, 2015, vol. 46B, pp. 74-82.

52. Z. Tong, J. Qiao, and X. Jiang: Ironmak. Steelmak., 2017, vol. 44, pp. $237-45$.

53. F. Harrell: Regression Modeling Strategies: With Applications to Linear Models, Logistic Regression and Survival Analysis, Springer, New York, NY, USA, 2001.

54. K. Baumann: Trends Anal. Chem., 2003, vol. 22, pp. 395-406.

55. K. Baumann and N. Stiefl: J. Comput. Aided Mol. Des., 2004, vol. 18 , pp. $549-62$.

56. M. Allibert, H. Gaye, J. Geiseler, D. Janke, B.J. Keene, D. Kirner, M. Kowalski, J. Lehmann, K.C. Mills, D. Neuschütz, R. Parra, C. Saint-Jours, P.J. Spencer, M. Susa, M. Tmar, and E. Woermann: Slag Atlas, 2nd ed., Verlag Stahleisen GmbH, Düsseldorf, 1995.

57. C. Runge: Math. Ann., 1895, vol. 46, pp. 167-78.

58. A. Condo: Doctoral dissertation, KTH Royal Institute of Technology, Stockholm, Sweden, 2018.

Publisher's Note Springer Nature remains neutral with regard to jurisdictional claims in published maps and institutional affiliations. 